\title{
Cognitive capacities and composite cognitive skills in individuals with Usher syndrome type 1 and 2
}

\author{
Cecilia Henricson
}

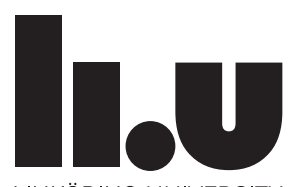

LINKÖPING UNIVERSITY

Linköping Studies in Arts and Science No. 651

Studies from the Swedish Institute for Disability Research No. 72 Linköping University,

Department of Behavioural Sciences and Learning Linköping 2015 
Linköping Studies in Arts and Science • No. 651

Studies from the Swedish Institute for Disability Research • No. 72

At the Faculty of Arts and Sciences at Linköping University, research and doctoral studies are carried out within broad problem areas. Research is organized in interdisciplinary research environments and doctoral studies mainly in graduate schools. Jointly, they publish the series Linköping Studies in arts and Science. This thesis comes from the Swedish Institute for Disability Research at the Department of Behavioural Sciences and Learning.

Distributed by:

Department of Behavioural Sciences and Learning

Linköping University

SE-581 83 Linköping

Cecilia Henricson

Cognitive capacities and composite cognitive skills in individuals with Usher syndrome type 1 and 2

Edition 1:1

ISBN 978-91-7685-999-5

ISSN 0282-9800

ISSN 1650-1128

CCecilia Henricson

Department of Behavioural Sciences and Learning, 2015

Printed by: LiU-Tryck, Linköping 2015 
Table of Content

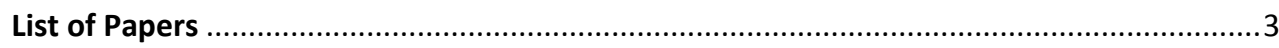

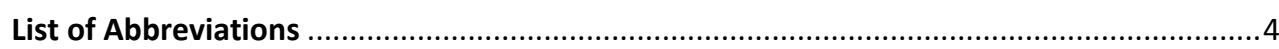

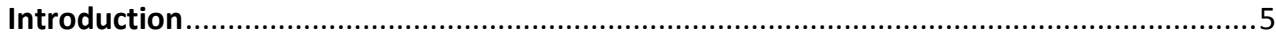

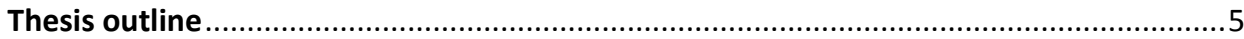

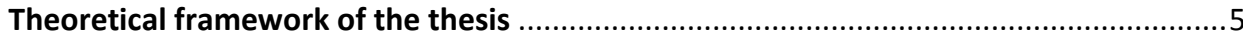

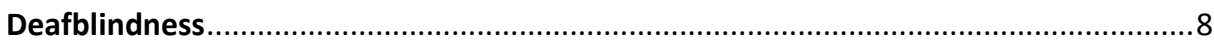

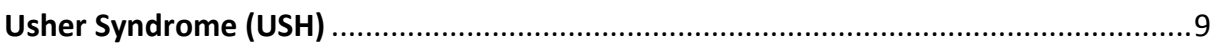

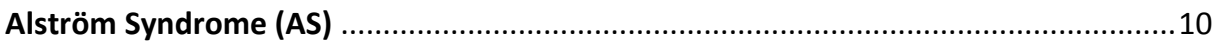

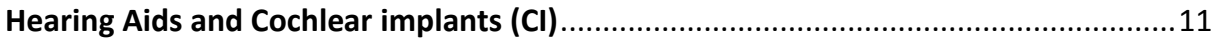

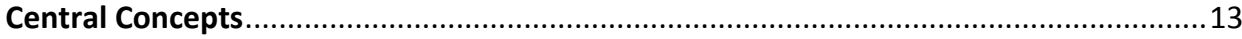

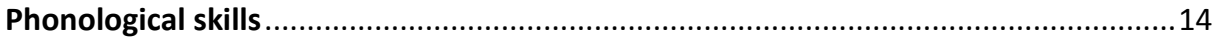

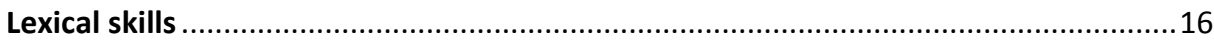

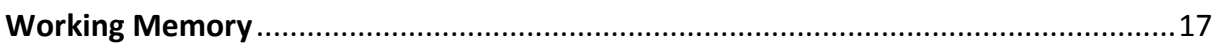

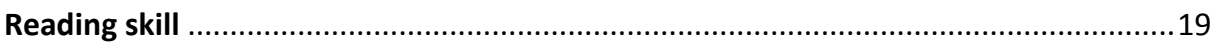

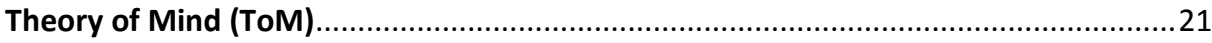

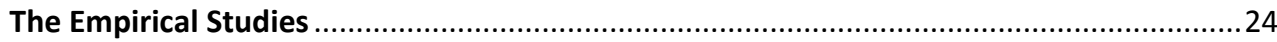

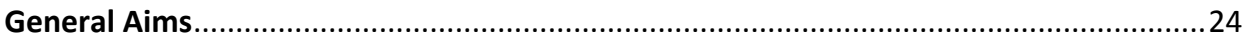

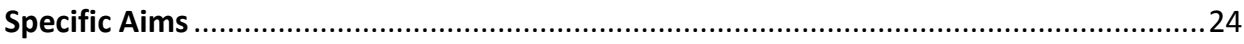

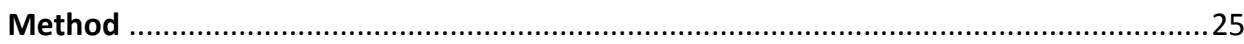

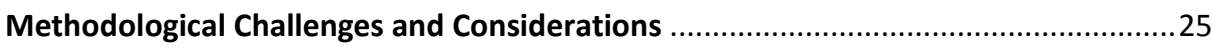

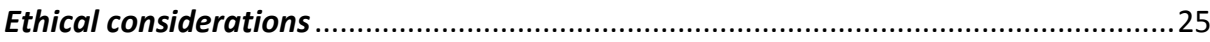

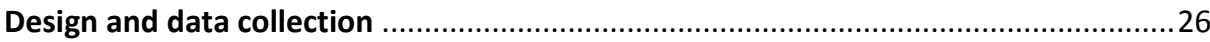

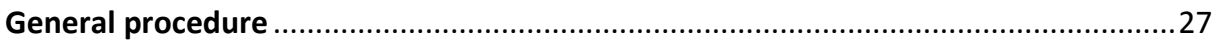

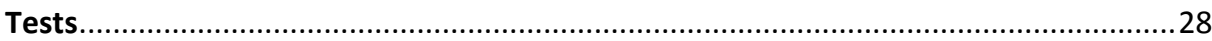

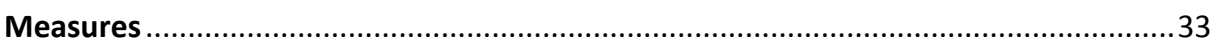

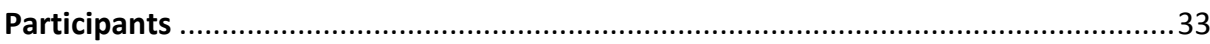

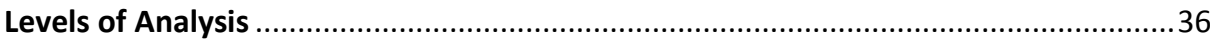

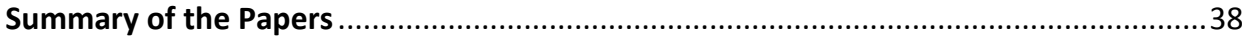

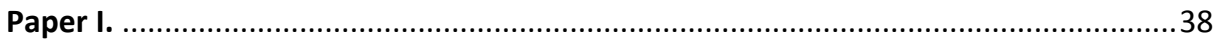

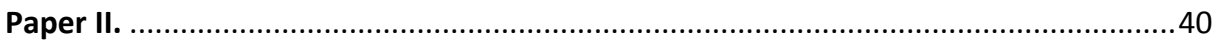

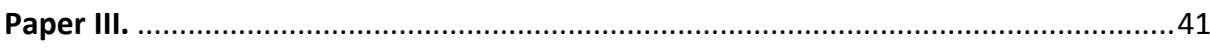

Paper IV. 


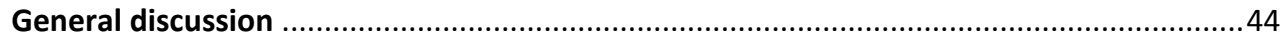

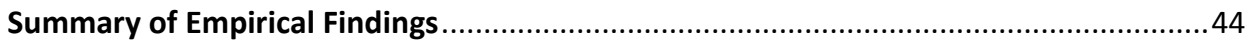

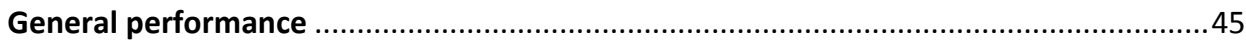

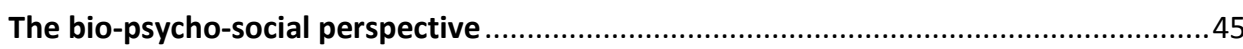

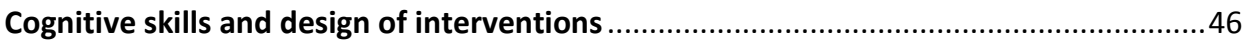

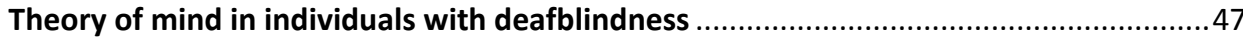

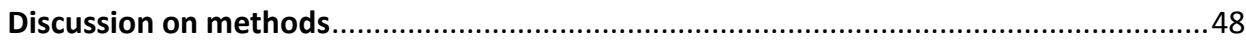

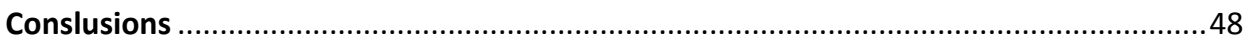

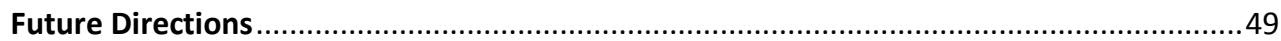

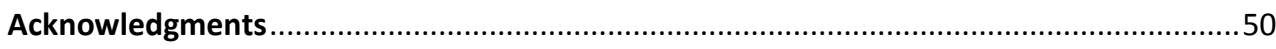

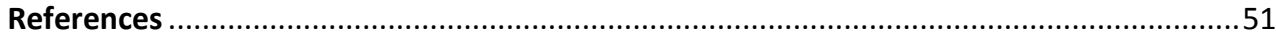




\section{List of Papers}

\section{Paper 1}

Henricson C., Wass M., Lidestam B., Möller C., Lyxell B. (2012) Cognitive skills in children with Usher syndrome type 1 and cochlear implants. International Journal of. Pediatric.

Otorhinolaryngology, 76, 1449-57.

\section{Paper 2}

Henricson C., Lidestam B., Möller C., Lyxell B. Reading skill in five children with Usher type 1 and cochlear implants. (manuscript)

\section{Paper 3}

Henricson, C., Lidestam, B., Lyxell, B., Möller, C. (2015). Cognitive skills and reading in adults with Usher syndrome type 2. Frontiers in Psychology, 6(326). doi: 10.3389/fpsyg.2015.00326

\section{Paper 4}

Henricson C., Frölander H-E., Möller C., Lyxell B. Theory of Mind and cognitive function in adults with Usher and Alström syndromes. (manuscript) 


\section{List of Abbreviations}

AS: Alström Syndrome

$\mathrm{Cl}$ : Cochlear Implant

HA: Hearing Aid

HI: Hearing impairment

$\mathrm{HI}+\mathrm{HA}$ : Hearing impairment rehabilitated with Hearing aids

HL: Hearing Loss

NH: Normal Hearing

NHV: Normal Hearing and Vision

P.corr.c: Percent Correct Consonants

Phon.WM: Phonological Working Memory

SRN: Serial Recall of Non-words

ToM: Theory of Mind

USH: Usher syndrome

USH1: Usher syndrome type 1

USH1+Cl: Usher syndrome type 1 with $\mathrm{Cl}$ as treatment for the profound deafness

USH2: Usher syndrome type 2

WM: Working Memory 


\section{Introduction}

The present thesis investigates the impact of the combination of hearing and visual impairment on a set of basic cognitive abilities, and two composite abilities. The population with Usher syndrome (USH) was selected, as the conditions of the syndrome are relatively well known with regard to genetics and medicine, but very few studies have focused on the population from a cognitive perspective. Research within the area of cognitive hearing science has demonstrated that better understanding of the interplay between cognitive skills and sensory input can be important to the design of treatments, devices, and interventions aimed at improving communication (e.g., Alt \& Suddarth, 2012; Baddeley, 2003; Hua, Karlsson, Widén, Möller, \& Lyxell, 2013; Ng, Rudner, Lunner, Pedersen, \& Rönnberg, 2013; Rönnberg, Rudner, Lunner, \& Zekveld, 2010). In the present thesis levels of phonological skill, lexical skill and working memory capacity in children with Usher syndrome type 1 (USH1), and in adults with Usher syndrome type 2 (USH2) has been examined. Furthermore, two composite cognitive skills were selected for investigation: reading skill (in both the children and adults), and theory of mind (in the adult group).

\section{Thesis outline}

The main theme of the present thesis is the level of functioning of three basic cognitive abilities (i.e., lexical skill, phonological processing, and working memory), which are all affected by degree and quality of sensory input (i.e., vision and hearing). The thesis thus starts with describing the neuropsychological theories and concepts that are at its foundation. This is followed by descriptions of deafblindness, USH, Alström syndrome (AS), and technical devices for treatment of hearing impairment and deafness. These phenomena are described as they could be expected to impact on the neuropsychological level, causing performance on cognitive tests to be different to that of control groups. The next section describes the cognitive skills that are in focus in the thesis, and contains accounts of previous research investigating sensory impairments in relation to these cognitive skills. The thesis then moves on to present an overview of the empirical results, and finishes with a discussion attempting to tie together the previous knowledge on sensory impairments and cognitive skills with the empirical findings from the studies included in the thesis. To complete the thesis, there are some suggestions for future research.

\section{Theoretical framework of the thesis}

The topic of the present thesis belongs to the field of disability research, and more specifically, research on cognition, hearing and deafness, and deafblindness. Disability research describes functioning, impairment and disability in relation to their biological, psychosocial, social and cultural aspects (Möller, 2003).

At the foundation of this thesis is the neuropsychological concept of brain plasticity. It is common knowledge today that there changes in the physiology of the brain occur in response to a person's behavior and surrounding. For example, training of a skill, such as for instance playing a musical instrument, will increase activity in the areas of the brain responsible for fine motor control, as well as areas involved in the perception, processing, 
and learning of music (Pantev et al., 2003; Gaab \& Schlaug, 2003). There are several examples of changes or reorganization of the brain detected in imaging studies using functional magnetic imaging (fMRI) or event related potentials (ERP), as a result of early, profound sensory impairment. For instance, areas of the brain typically involved in auditory processing have been found to instead be activated in response to visual stimuli in deaf individuals (Lomber et al., 2010; Kral \& Eggermont, 2007), or areas which otherwise would process visual information responding to auditory information in individuals with congenital blindness (Hötting \& Röder, 2009),.

The amount and quality of stimuli that the brain receives influences the neurological networks of the brain, which is the core feature of plasticity (Hensch, 2005). Those areas of the cortex that are involved in perception and the first steps of processing of sensory information are called primary areas. These primary areas of the cortex are at their highest peak of plasticity during the infant years (Hensch, 2005; Kral \& Eggermont, 2007).

Disturbances in sensory intake, or lack of input from a sense, as is the case in congenital hearing impairment or congenital profound deafness, is highly likely to give rise to adaptations and changes of all areas of the brain which normally would deal with that sensory information (Lomber et al., 2010; Lee et al., 2007; Sharma et al., 2009; Doucet et al., 2006). A strong hypothesis is that, in turn, this cross-modal plasticity will have an effect on the development of those cognitive abilities which rely on the basic sensory processing (Berk, 2009). Thus, a sensory deprivation seems to cascade through, and impact on, the development of all cognitive abilities relying on that sense (See figure 1 for an illustration of cascading effects).

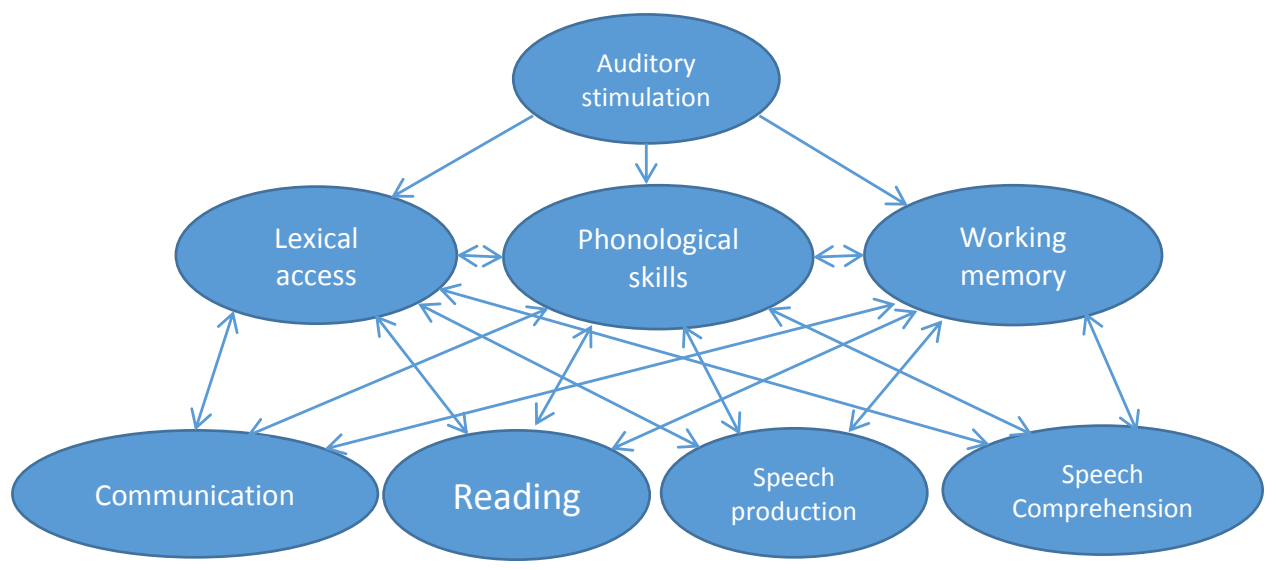

Figure 1: Cascading effects from auditory stimulation on development of cognitive functions. 
An example is that of areas of the brain, which normally are involved in the processing of sound, but which in pre-lingually deafened individuals are activated in response to specific visual stimuli, such as the signs of sign language (Lomber et al., 2010; Lee et al., 2007). The altered development of basic cognitive skills is likely to have an impact on the development of more composite cognitive skills, such as language (Löfkvist et al., 2014) and reading (Nakeva von Mentzer et al., 2013). To what extent and in what ways these complex abilities will be affected, will however be dependent on many different factors within and outside of the individual, such as personality, motivations, and communication strategies and competence of the friends and family as well as rehabilitative services and support. Likewise, if an individual is congenitally visually impaired, the development of the brain areas typically involved in processing of visual stimuli, and the cognitive abilities linked to these, will develop in a different manner than in a person with normal vision (Hensch, 2005; Rokem \& Ahissar, 2009). Similarly, there is evidence of plastic changes in individuals with long term visual impairment, indicating that areas of the brain previously processing visual information will instead be involved in auditory information processing (Théoret et al., 2004).

Language processing, regardless of modality of language (visual, as in signing, or auditory, as in speech), is a complex cognitive activity, reliant on several networks and structures of the brain (Bennett \& Hacker, 2006; Berk, 2009). Language is considered to have two sensitive periods, or windows of plasticity, the first from birth up to 4-5 years of age, and the second from around 5 years up to mid adolescence (Berk, 2009). Development of the cognitive skills in spoken language to some extent runs parallel to the progression of auditory processing skills, and during the first sensitive period of language the development of those processing abilities is clearly at its peak. The sensitive periods of language development are also evident regardless of modality of language, and display the same content in both spoken and sign language (Lederberg et al., 2013). The first sensitive period of language ends at about 4-5 years of age, and there is ample empirical evidence to show that limited access to, or lack of, language and communication during this first sensitive period in most cases leads to deviant or delayed development of language (Peterson et al., 2010; Dorman et al., 2007; Lederberg et al., 2013) or even language impairment (Peterson et al., 2010; Engel de Abreu et al., 2011).

During the first three years of life the development of working memory concurs with the expansion of vocabulary and the building of grammatical skills (Engel de Abreu et al., 2011; Hayes, Geers, Treiman, \& Moog, 2009; Nakeva Von Mentzer, 2014). These latter skills, as well as pragmatic language skills, display a developmental burst during the following years until the closing of the first sensitive period (Berk, 2009; Nakeva Von Mentzer, 2014). The second sensitive period ends during the middle of the teenage years, and languages that have been learnt after this age are wired in different structures and networks of the brain compared to languages learned prior to this age (Ruben \& Schwartz, 1999). Löfkvist et al. (2014), Mentzer (2014), and Ruben and Schwartz (1999) all highlight the importance of 
access to a full, nuanced and rich language during these sensitive periods in order for a typical language development to occur.

Individuals with USH experience a combination of congenital hearing impairment/profound deafness and visual impairment during the lifespan. Hence, the consequences of these conditions on cognitive skills are of central importance to this thesis. All individuals with Usher syndrome are born with hearing impairment, albeit of different severity and progression, and all develop severe visual impairment. The present work is an attempt to develop the beginnings of an understanding of how the sensory processes in USH might impact cognitive abilities. This knowledge is achieved by comparing the performance of the group with USH to participants with normal hearing and normal vision. The two included groups with USH are also compared to control groups with similar levels of hearing impairment, or more severe deafblindness, and not only to individuals with normal hearing and vision (NHV), thus giving another caveat to the description of the cognitive abilities in the group with $\mathrm{USH}$. The children with $\mathrm{USH} 1+\mathrm{Cl}$ were described in relation to children with other types of deafness and $\mathrm{Cl}$ and to children with $\mathrm{HI}+\mathrm{HA}$, and the adult group with USH2 was described in relation to a group with Alström syndrome.

\section{Deafblindness}

The Nordic definition of deafblindness (DB) states that DB is a specific condition in that the combination of hearing loss and visual impairment impacts on daily life and self-reliance to such a degree that the person becomes dependent on help from others, as well as from society, in order to reach full participation. The exact definition states:

"DB is a specific disability. DB is the combination of visual and hearing impairment. DB limits a person's ability to participate in activities, and restricts full participation in society to such an extent that society needs to facilitate by providing specific interventions, by adapting the environment and/or offer technical solutions." (nkcdb.se, click the tag 'DÖVBLINDHET')

The Nordic definition further develops the definition of deafblindness, describing the central importance of vision and hearing for the access of information. In the developed description it is also clearly stated that some environmental conditions ease the difficulties arising due to the visual loss and hearing impairment, while other situations worsen the issues. NKCDB highlight the importance of evaluating each situation on its own, since the level of impairment can vary for individuals with DB. This line of reasoning is congruent with the International Classification of Functioning, Disability and Health (ICF), a framework developed by WHO in order to describe health and disability at both the individual and population level (Möller, 2003). A purpose of ICF, and definitions developed in line with the framework, is to point out the complexity of disabilities, and the need to apply holistic and interdisciplinary perspectives in order to better understand the impact of an impairment in different settings and individuals. Typically, though, the definitions which have been applied in empirical studies of DB have been less holistic and fit to the perspective of the study in a more narrow fashion, such as a medical definition only (Ask Larsen \& Damen, 2014). The 
definitions of deafblindness (DB) used in research on DB and congenital DB were recently investigated and the results were published in a review by Ask Larsen and Damen, (2014). The authors found the definitions applied to vary, which makes comparisons across studies and generalizations of findings difficult. Ask Larsen and Damen (2014) recommend that at least one of seven minimal criteria should be used in order to define DB, thus facilitating comparisons across studies. In the present thesis, definition of DB itself has been secondary to the definition of the selected study groups, as the aim was to describe aspects of cognitive abilities and skills in the largest population with genetically caused DB, i.e., individuals with Usher Syndrome.

Combined visual and hearing impairment is conceptualized as DB when the combination of the two impairments have an impact which goes beyond what either impairment would have had on its own (Möller, 2007). However, the term does not mean total blindness in combination with profound deafness, although this is a common misunderstanding. Here the concept is used to designate the condition where the combined visual and hearing impairment impacts the person's ability to be self-dependent, and severely limits access to information in such a way that if the person does not receive society's assistance s/he is at great risk of being excluded from the everyday activities as well as from other processes (Möller, 2003; Wahlqvist, Möller, Möller, \& Danermark, 2013). DB is defined in the same way throughout this work. When this definition is applied with the participants of the present thesis, 11 of the adult participants, and one of the children, could be included in the category of individuals with DB. The other six children with USH1, and two of the adults with USH2, did at the time of data collection not have a combination of visual loss and hearing impairment severe enough to fit into the Nordic definition of DB.

The major causes of DB are genetic conditions, which can lead to DB at any time during the lifespan (Möller, 2007). Syndromes causing DB typically have low prevalence (Dammeyer, 2010; Möller, 2007), and in a country with a small population, like Sweden, there will only be small populations. Some syndromes, such as Alström syndrome (AS), will only have a few individuals within each generation (Frölander et al., 2014). When a person with DB appears at the rehabilitation centers and services it may be the first time the professionals there are confronted with a syndrome leading to combined visual loss and hearing impairment. Hence, the need for developing knowledge and organizing already existing knowledge in sustainable and accessible ways is of great importance, in order for the health care to be able to provide good service and intervention.

\section{Usher Syndrome (USH)}

Usher syndrome has a global prevalence of about 3.6/100 000 individuals, and is divided into three types with different progression of symptoms (Pennings, 2004; Sadeghi et al., 2004b). There is variation in which of the three clinical types of the syndrome that is most prevalent in a region of the world, and in Sweden types 1 and 2 are the most common forms (Pennings, 2004; Sadeghi, 2005). Individuals with USH1 are profoundly deaf at birth and lack 
balance function. The progressive visual loss is due to Retinitis Pigmentosa (RP), which leads to poor contrast sensitivity, light sensitivity, night blindness, and to loss of visual field (tunnel vision), but also to some extent loss of visual acuity. RP in USH1 begins with mild symptoms, such as night blindness and sensitivity to light in the ages 5-8 years. The state of functional blindness is generally apparent at 30-40 years of age, but a narrow, central visual field of about 10 degrees remains, though it usually diminishes slowly to around 5 degrees at 60 years of age (Möller, 2007; Sadeghi, Kimberling, et al., 2004). Cataracts are also common in USH (Möller, 2007; Sadeghi, Kimberling, et al., 2004). In USH2, individuals are born with a moderate to severe hearing loss. The hearing loss remains stable over the lifespan, except for the expected age decline of hearing (Sadeghi et al., 2004a). The balance function is intact, while progression of RP is similar to that in USH1, though USH2 is usually diagnosed at a later stage, typically in the late teens ( Möller, 2007). Individuals with USH3 display progressive hearing loss, progressive loss of balance function, and RP.

USH is caused by different genetic mutations in several genes responsible for the coding of proteins that construct the hair cells of the inner ear and balance organ, as well as the proteins in the rods of the retina (Kremer et al., 2006; Boëda et al., 2002; Cremers et al., 2007). The inner ear and the eye are the only affected bodily structures, and symptoms are limited to the functions of these structures. In Usher syndrome the hair cells of the cochlea develop, but malfunction occurs either due to defective tip-links or defects in the structures responsible for ion circulation, necessary for the firing of nerve pulses (Boëda et al., 2002; van Wijk et al., 2004; Kremer et al., 2006; Giacomello et al., 2011). Possibly, individuals with USH of type 1 or 2, respectively, develop hearing as fetuses, but then become either profoundly deaf or develop a hearing impairment, as a result of their genetic condition. The progress of the hearing loss would in this case be similar to, but more rapid than, the progressive loss of vision. A speculation would be that if there is hearing in the fetal stage, it could have implications for the state of the auditory nerve and auditory cortex, particularly in the case of USH1. As described previously regarding the plasticity of the brain, those areas of cortex which receive stimulation develop more (Berk, 2009; Hensch, 2005). Hence, having had auditory stimulation could cause the process of pruning, during which unconnected and unused neurons are terminated to the benefit of those connected and stimulated, to be less progressed in infants with USH1 compared to infants with other types of deafness. In this case, children with USH1 would have slightly better conditions for implantation with a $\mathrm{Cl}$, as the state of the auditory nerve is assumed to be a predictor of outcome (Giraud \& Lee, 2007; Lazard et al., 2012).

\section{Alström Syndrome (AS)}

AS has a much lower prevalence than Usher syndrome, so low that the prevalence has not been defined, and only about 900 individuals have been diagnosed worldwide (Socialstyrelsen, 2014). AS is also a genetic condition, but it causes a ciliopathy impacting several bodily structures and causes multi-systemic illness (Frölander et al., 2014; Joy et al., 2007; Marshall et al., 2007). Among the major health issues are malfunctions of the eye, 
inner ear, heart, liver, and kidneys, and individuals with the syndrome have a short life expectancy (Marshall et al., 2007; Joy et al., 2007).

AS also causes deafblindness, but the progression of the visual and hearing impairments are very different from USH. Until recently, the knowledge of how the hearing impairment develops had not been systematized, but in a study by Möller et al. (in press) audiograms on several patients with AS have been congregated. The researchers show that the hearing loss progresses from mild to severe over the course of 25-30 years. The RP in AS is very aggressive and vision rapidly deteriorates to complete blindness in the adolescent years (Marshall et al., 2007).

Similar to the research on the group with USH, the studies regarding AS have typically focused on physiological and genetic aspects of the syndrome. The study by Frölander et al. (2014) is one of the first investigating cognitive abilities, primarily theory of mind (ToM), in the group. ToM refers to the ability to understand the reasons and motivations of other persons' feelings and actions (e.g., Happé, 1994; Low \& Perner, 2012). The findings of Frölander et al. (2014) indicate that individuals with AS display lower levels of this complex ability, and are in line with clinical observations of the interactions with this group of individuals as being qualitatively different from interactions with other patients with deafblindness.

\section{Hearing Aids and Cochlear implants $(\mathrm{Cl})$}

There has been an extreme technological development of hearing aids over the past decades (Arlinger et al., 2009; Schweitzer, 1997). Parallel to the technological advancements research has developed new knowledge on sensorineural hearing loss (Arlinger et al., 2009; Saremi \& Stenfelt, 2011). Neither the $\mathrm{Cl}$, nor the hearing aid can restore hearing to normal level, but where the $\mathrm{Cl}$ bypasses a damaged inner ear, the purpose of the hearing aid is to amplify and adapt the auditory signal so that it can be perceived through an ear with a conductive hearing loss, or a sensori-neural hearing loss less severe than that which needs treatment with $\mathrm{Cl}$ (Arlinger et al., 2009). The possibility to use advanced digital signal processing in small processing units has meant vast improvements in the help that patients receive. With digital amplification and signal processing in the hearing aid the signal can be better adapted to make sound audible to the person with $\mathrm{HI}$ ( $\mathrm{Ng}$ et al., 2013). The problems which digital processing techniques aim to relieve are smearing (the blending together of sounds that occur close together in time, frequency, and loudness), poor temporal resolution, and hyper-acusis (over-sensitivity to noise), all of which occur as a result of the malfunction of the outer and inner hair cells of the cochlea. However, even though there has been progress, the issues have not yet been entirely solved. Also, advanced signal processing causes artifacts to the signal, such as distortions of the sound, and is not beneficial for outcome in terms of for example speech comprehension in all individuals with hearing impairment ( $\mathrm{Ng}$ et al., 2013; Arlinger et al., 2009). It appears that the cognitive prerequisites of an individual matters in what kind of hearing aid and signal processing will 
be most useful and beneficial for treating her/his hearing impairment (Arlinger et al., 2009; Rudner et al., 2011).

Treatment with a cochlear implant $(\mathrm{Cl})$ is applied when there is a lack, or malfunction, of the hair cells in the cochlea so severe that an amplified and processed auditory signal through hearing aids gives little or no benefit to the patient (Lyxell et al., 2013). The following description of the device and functions of the $\mathrm{Cl}$ are based on information from the NIDCD Fact Sheet on $\mathrm{Cl}$ from the U.S. department on Health and Human Services, the Institute on Deafness and other Communication Disorders (NIH Publication No. 11-4798, 2011).

$\mathrm{A} \mathrm{Cl}$ consists of two parts, of which the outer part is a signal processor but also contains a signal transmitter. The implanted parts consist of a receiver, a sender, and an electrode array which is surgically inserted into the cochlea, where it stimulates the spiral ganglion cells. The frequency resolution with a $\mathrm{Cl}$ is very low compared to that of a normal ear, or even to that of hearing with a hearing aid, since there is only a maximum of 24 channels available in comparison to the 17000 outer and inner hair cells in a healthy inner ear. Also, even though the necessary signal processing is done as fast as possible, individuals who listen through a processor will be subjected to a small lag compared to those with normal hearing. Despite these limitations, the auditory stimuli provided by $\mathrm{a} \mathrm{Cl}$ is sufficient to sustain development of the cognitive abilities associated with auditory processing, and the more complex skills relying on hearing, such as spoken language.

When the possibility of treatment of deafness with $\mathrm{Cl}$ started to reach clinical practice it was not uncontroversial, and there were many protests against the implantation of deaf children (Gonsoulin, 2001). The antagonists of $\mathrm{Cl}$ pointed, among other things, to the risks of the surgery, the risk of the hearing not being good enough for sufficient speech learning, though at the same time there would be no learning of sign language (as all focus would be on hearing), as well as to the fact that in case of malfunction of the implant the individual would become deaf, without access to a functional mode of communication (Gonsoulin, 2001; Mauldin, 2013). The argumentation for and against $\mathrm{Cl}$ also revolved around the issue of how deafness was (and is) viewed by the hearing society (Iversen, 2011). Parts of the Deaf community reacted strongly against the conception of deafness being a disability that should be 'fixed' by medical treatment (surgery), refuting this medical model of deafness (Iversen, 2011). Debate was extremely polarized during the late 1990's, but as the situation is today, those opposing cochlear implants have had to reach a gradual acceptance of the treatment. Partly, this is because $95 \%$ of the children born with deafness are born to parents with normal hearing, who lack both knowledge in sign language and contact with the Deaf community and therefore choose a Cl (Nakeva Von Mentzer, 2014). Also, the development of implants and rehabilitative services have continued and proven increasingly successful for development of hearing and spoken language, thus making it a comprehensible option for a majority (Mauldin, 2013; Nakeva Von Mentzer, 2014). 
For individuals with USH the improvements and continuing development of hearing aids and $\mathrm{Cls}$ have been, and are, beneficial for the rehabilitation of their hearing. If the hearing loss in USH was not treated, the DB would become more severe, potentially leading to higher degrees of communicative difficulties, exclusion from social contexts, and also higher levels of insecurity, as important auditory information from the environment would be missing (e.g., cars on the street, shouting, etc.). The profound deafness in children with USH1 is diagnosed during infancy today and can hence be treated with a $\mathrm{Cl}$, giving access to the sounds of the environment as well as to spoken language. Likewise, the more advanced hearing aids and additional technical aids associated with them (for example, telecoils and FM-systems; radio communication units specifically designed for hearing aid reinforcement) can be assumed to be of great use for most individuals with USH2 in maintaining access to and use of spoken language for communication, and for accessing auditory information.

\section{Central Concepts}

The present thesis contains concepts adherent to several research fields, such as medicine, molecular biology and genetics, and cognitive hearing science. The concepts most central to the thesis will be explained under separate headings below, however, as the thesis aims to describe cognitive functioning the cognitive theories and concepts applied are given more space.

Cognitive psychology encompasses the human thought processes, such as decision making, logical reasoning, remembering and memory, communication, and reading (Eysenck \& Keane, 2003). Each of these concepts could be considered to be composite cognitive skills, consisting of sets of basic cognitive skills that need to interact in a seamless manner in order for the complex function to run smoothly. For example, the ELU-model by Rönnberg et al. (2013) represents an attempt to describe the cognitive skills required, and in what fashion they work together, in order to achieve speech comprehension. Cognitive abilities develop during childhood, in interaction with the stimuli experienced and the prerequisites of the individual. Most skills continue to be refined over the adult lifespan (Berk, 2009), although with ageing comes an age-related decline. The basic cognitive abilities and skills are typically aimed at processing sensory input (Eysenck \& Keane, 2003). As has been described above; should the source of input be limited or lacking, such as in the case of hearing impairment or profound deafness or blindness, these basic abilities may not develop in the typical way. Throughout this work the focus is on phonological skills, lexical skills, and working memory, considered to be basic cognitive abilities dependent on hearing, and in specific instances on vision, in order to develop to their full potential and capacity. These three basic cognitive skills underpin several more complex abilities, such as spoken language (Alloway et al., 2004; Engel de Abreu et al., 2011), reading (Lundberg, 2009), and theory of mind (ToM) (Schick et al., 2007). There is extremely little previous knowledge on how these cognitive skills would develop or be expressed by populations with deafblindess. The assumption, based on the findings of the impact that hearing impairment and visual impairment, 
respectively, have on cognitive development, would however be that deafblindess also affects the development of cognitive abilities.

Phonological skills

Phonological skills are, in this work, defined as the set of cognitive abilities dealing with the storage and processing of speech sounds (cf., Nakeva von Mentzer et al., 2013; Lyxell et al, 2009; Löfkvist et al., 2014). The concept as it is applied here does not encompass the processes that generate phonological output, but attempts to limit the application to the cognitive processes resulting in successful decoding of a speech signal into its separate sounds, similar to the definition used by Wass (2009). The phonological skills of spoken language are dependent on auditory stimulation in order to develop in a typical way (Boets, Wouters, van Wieringen, De Smedt, \& Ghesquière, 2008; Lazard et al., 2012). As previously stated, the ear is fully developed already at the third trimester of pregnancy, making hearing one of the earliest developed senses (e.g., Berk, 2009; Mampe, Friederici, Christophe, \& Wermke, 2009). Infants are able to perceive and discriminate between most of the phonemes used in natural languages, but as language experience accumulates, the ability to discriminate narrows during the first year of life, and instead the child becomes more sensitive to the salient phonological aspects of her/his primary language (Doucet et al., 2006). The ability to identify speech sounds is highly important for language development and is at the foundation of spoken language development (Marchman \& Fernald, 2008). In typically developing individuals the speech sounds will form an inner library of long term memory representations to which incoming sequences can be matched (Alt \& Suddarth, 2012; Goldrick \& Rapp, 2007). These long term memory representations can, among other things, then be used to relieve the phonological storage component of working memory and release capacity for other tasks (Baddeley, 2003; Baddeley, 2012; Rönnberg et al., 2010). As more and more speech sounds can be matched to their representations, the identification of words becomes easier, and more capacity for understanding and learning their meaning becomes available (Löfkvist et al., 2014).

However, if there is a hearing impairment the access to speech sounds is restricted, and separation and identification of them is likely to be more difficult. Thus, building stable phonological representations may take longer than for an individual with normal hearing (e.g., Alt \& Suddarth, 2012; Briscoe, Bishop, \& Norbury, 2001; Lyxell et al., 2013). Research on children with $\mathrm{HI}+\mathrm{HA}$ and on children with $\mathrm{Cl}$ has demonstrated that a higher degree of experience of words, and a generally higher degree of stimulation, is needed in order for these groups of children to acquire stable and exact phonological representations (e.g., Alt \& Suddarth, 2012; Briscoe, Bishop, \& Norbury, 2001; Lyxell et al., 2013). Regarding children with $\mathrm{Cl}$, age at implantation is also a highly important factor for the development of phonological skills, and earlier implantation has generally been found to be more beneficial for development of spoken language skills rather than later implantation (Peterson et al., 2010; Nicholas \& Geers, 2007). Children implanted at or above the age of 4-5 years typically display a delayed or deviant development of phonological skills (Peterson et al., 2010; 
Nicholas \& Geers, 2007; Geers et al., 2008). As stated previously, the brain adapts to the amount and quality of stimuli it receives, and indeed, there are several findings of crossmodal reorganization of the brain of children with an age of implantation above 4-5 years (Kral \& Eggermont, 2007; Kral \& Sharma, 2012; Sharma et al., 2009). The studies by Sharma et al. (2009), Kral and Sharma (2012), and Kral and Eggermont (2007) also demonstrate that implantation before the age of 2 years seems to be sufficient in order for the brain to develop an auditory response pattern that is typical. The research by, for example, Lyxell et al. (2009), Asker-Arnason et al. (2010), Nakeva von Mentzer et al. (2013), Löfkvist et al. (2014), and Nicholas and Geers (2007) on children with deafness but no other co-existing disability also indicates that children who had early implantation, that is, before the age of 2 years, are more likely to develop language skills to a level similar to that of their peers with $\mathrm{NH}$. There are also findings demonstrating that phonological skills may deteriorate over time in adults with long duration of hearing loss (Andersson, 2001; Classon et al., 2013; Lazard et al., 2012), indicating that continuous stimulation and access to speech sound is necessary in order to maintain these skills.

The term phonological processing is also used throughout the thesis to denote essentially the same concept as phonological skills. However, phonological processing can be considered as evoking the cognitive perspective more strongly than the term 'phonological skills'. The concept 'phonological processing' is typically applied in studies with an explicit focus on the memory processes in speech perception and/or comprehension (e.g., Rudner, Rönnberg, \& Lunner, 2011; Rönnberg, Rudner, Lunner, \& Zekveld, 2010; Santos, Bueno, \& Gathercole, 2006).

Phonological skills are typically measured by tasks taxing the ability to discriminate between, or match, or manipulate speech sounds (Briscoe et al., 2001; Furnes \& Samuelsson, 2011). In a discrimination task, the object is to identify whether pairs of words are identical, or whether a word includes a specific sound or not (Gathercole et al., 2006; Jacquemot et al., 2006). When the goal is to match speech sound the task would, for example, be to identify rhymes or syllables in pairs of words (Alt \& Suddarth, 2012; Blaiklock, 2004). Finally, in a manipulation task, the problem to solve could be to blend or rearrange syllables in a word, thus creating another word consisting of the same syllables/sounds but in a different order (Høien et al., 1995; Nakeva von Mentzer et al., 2013). The task could also be to remove a specific syllable or section of the word. Manipulation tasks are typically presented in audio, and the answer is commonly oral, as presenting the word in written form would tax other skills (Nakeva von Mentzer et al., 2013; Briscoe et al., 2001). When oral answers are given, the quality of phonological output becomes a confounding factor, and hence scoring needs to be done carefully and with consideration to the participant's typical pronunciation, dialect, or speech impediment (Archibald \& Gathercole, 2006). Atypical phonological output is relatively common in individuals with pre-lingual hearing loss (Vallar et al., 1997; Archibald \& Gathercole, 2006). 
In order to avoid another confounding factor, i.e., language competency, when testing phonological skills, non-words or one syllable speech sounds are typically used. Real words activate more cognitive processes than non-words, such as, lexical and semantic processes. Hence, a real word is easier to identify, remember, and recall, as it activates long term memory representations of the concept it represents (Baddeley, 2012; Baddeley, 2003; Engel de Abreu et al., 2011) .

Since phonological skills are so intimately connected to hearing, the impact of visual impairment or blindness on the development and maintenance of the skills can be expected to be very limited. However, there is one way in which blindness could potentially impact phonological skills, and it is via reading (Dodd \& Conn, 2000; Greaney \& Reason, 1999). This will be discussed further on, under the heading 'Reading skill'.

\section{Lexical skills}

Lexical access is one aspect of lexical skills and refers to the processes dealing with the retrieval of the meaning of words and concepts. Lederberg, Schick, and Spencer (2013) as well as Rönnberg, Rudner, Lunner, and Zekveld, (2010) describe lexical processes as intertwined with the phonological. Both types of processes are necessary, and need to run efficiently, in the highly automatized process of speech comprehension. When the automatized process breaks down, due to a mishearing or to lack of knowledge of a specific word, intentional and specific processing, which occupies working memory capacity, is needed in order to disentangle the message (Rönnberg et al., 2013). Fast lexical access is an indication of an automatized process that develops during language acquisition in individuals with typical hearing (Spencer \& Tomblin, 2009).

Lexical access more specifically refers to the retrieval of language representations and semantic information from long-term memory (Gaskell \& Marslen-Wilson, 2002). In other words, lexical access is the term for the process of retrieving the memory representation of a word's meaning. For example, the word 'cat' evokes the semantic knowledge representations of a furry animal with pointed ears, a tail, whiskers and claws, that doesn't get along with dogs. The process runs in the other direction when we are engaged in speech production (Goldrick \& Rapp, 2007) and also, if we see the animal, the word 'cat' automatically springs to mind. Occasionally, these automatic and non-reflective processes fail, as is the case in the tip-of-the-tongue phenomenon, when a word of which we have perfect understanding and knowledge suddenly slips out of mind when it is needed (Shafto et al., 2007). This phenomenon can be partly explained by poor connection between the semantic and the phonological representations of the word (Shafto et al., 2007).

As previously stated, phonological skills, and in particular phonological working memory, are very influential on vocabulary development (Engel de Abreu et al., 2011; Baddeley, 2003; Gathercole, 2006). However, the relationship between vocabulary and phonological skills becomes more reciprocal as vocabulary increases, and typically at about three to five years of age, the process of retrieval becomes automatic requiring no conscious effort 
(Gathercole, 2006). An extensive vocabulary with efficient lexical access facilitates speech comprehension and makes it possible to predict the next concept/word from the context of the conversation (Moore et al., 2008; Jacquemot \& Scott, 2006). If the upcoming word then is a novel one, phonological processing is available and the word can more easily be learnt and remembered.

In children with $\mathrm{HI}$ or with $\mathrm{Cl}$ development of lexical skills can be deviant or delayed (Lyxell et al., 2009; Nakeva von Mentzer et al., 2013). Lyxell et al. (2009) found that children with Cl had equal performance with regard to accuracy, but they used a significantly longer time to retrieve the word than children with normal hearing. Löfkvist (2014) found children with $\mathrm{Cl}$ to perform better on expressive, rather than receptive, language tests, which is opposite to how children with $\mathrm{NH}$ perform. This could be an indication of less robust semantic knowledge (e.g., vocabulary) in children with $\mathrm{Cl}$. Thinking of the cascading effects of auditory stimulation, it seems clear that lexical skill would be impacted as a consequence of the delayed or deviant development of phonological skill. However, in what specific ways, to what extent, and what other factors that are also influential in the development of lexical skills are not yet completely understood (Löfkvist et al., 2014).

There has not been any extensive research on the impact of visual impairment on lexical access, but, as in the case of development of phonological skills, the impact would probably be minor, because the auditory mode is what is central to these skills, too.

\section{Working Memory}

The theoretical conceptualization of working memory (WM) applied in this thesis is the revised component model, originally created by Baddeley and Hitch in 1974 (Baddeley, 2012). The model describes the system of cognitive processes dealing with the current situation. WM is a memory system with limited capacity for storage and processing of information over a short period of time (Baddeley, 2012). This memory system is highly important to our functioning, and individuals with impaired WM typically display difficulties with planning, organization and execution of a number of different everyday tasks (e.g., Baddeley, 2012; Chan, Shum, Toulopoulou, \& Chen, 2008). There are models of WM stating that the cognitive resources of WM dealing with processing and storage of information are independent and domain-specific, which would mean that visuo-spatial information would not compete with auditory for processing or storage (Conway et al., 2007). However, in the component model of WM applied in the present thesis, there are two multi-modal components of WM and, hence, auditory and visual information compete for the resources of these units (Baddeley, 2012; Baddeley, 2003). If there is a deficiency in one of these multi-modal components, it will cause evident problems in everyday situations (Baddeley, 2012; Baddeley, 2003). Impairments in isolated components of WM, such as the visuospatial or phonological loop, are likely to give rise to more subtle difficulties. This view on the cognitive resources of WM can be considered as domain-general, which implies that, in a dual task situation, there has to be a trade-off between processing and storage (Maehara \& Saito, 2007; Baddeley, 2012; Conway et al., 2007). Thus, in case of a heavy processing 
load, there will be less resources available for storage, regardless of what modality the information that needs processing or storage is in. For example, the learning of a novel word might not occur for a person with hearing impairment, even if heard perfectly, if the word occurs in a film at the cinema. The cognitive capacity of WM could in such a situation already be occupied with processing all the visual stimuli, keeping track of the plot of the film, and disentangling the conversation between the characters. Possibly, if the person had not been watching the film but just listening to the sound track, there would have been enough capacity in order to attend to a novel word, so as to form the necessary mental representations of it and also remember it.

As the Figure 2 (below) of the component model displays, there are four WM components, and several pathways to long term memory (both to episodic and semantic long term memory) (Baddeley, 2012). The central executive and the episodic buffer deal with multimodal input, while the phonological loop and the visuo-spatial loop deal with auditory, visual and spatial information, respectively (Baddeley, 2003; Baddeley, 2012). The central executive monitors all processes within WM, and controls the distribution of cognitive resources in the sub-systems responsible for storage of visual/spatial and auditory information, respectively, as well as retrieval of long term memory representations (Baddeley, 2012).

The functions of the episodic buffer are primarily to bind the information from the phonological loop and the visuo-spatial loop together, and to retrieve and match this information with long term memory representations (Baddeley, 2012; Rönnberg et al., 2010). These functions are highly important, as access to previous knowledge, such as longterm memory representations of both speech and visual imagery, is necessary in order to solve the task of understanding the situation at hand, and deciding on action. According to the ELU-model developed by Rudner et al. (2011) and Rönnberg et al. (2010), speech understanding is achieved in the episodic buffer by the rapid, automatized binding of speech sounds to their long-term memory representations, and then of the recognized words to their semantical representation (their meaning). This rapid, automatized process requires little cognitive resources, but should the process be disturbed, for instance, by poor input signal or by distraction, then explicit processing, which demands resources, kicks in (Rönnberg et al., 2010). 


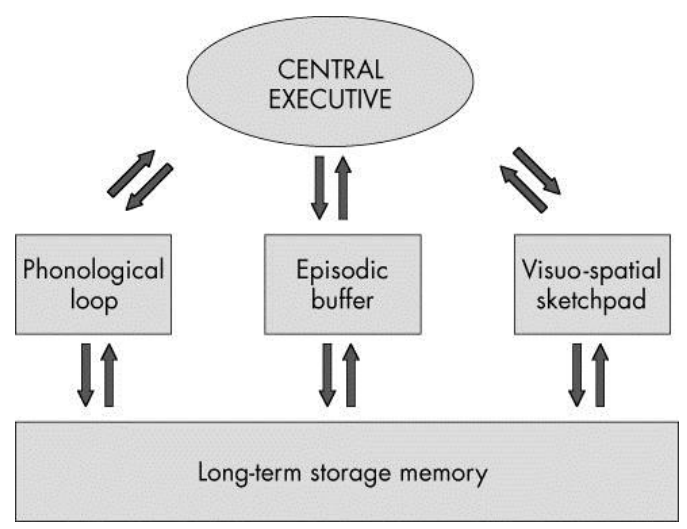

Figure 2: The component model of Working Memory (Baddeley, 2012)

Of specific interest to the present work is the phonological loop, which in turn contains two components, a rehearsal component, which deals only with repeating and refreshing the information in the other, the storage component of the phonological loop (Baddeley, 2012). The term phonological working memory is specifically used when referring to the process of temporary storage and (inner) rehearsal of speech sounds, as is done when listening to and then repeating series of one-syllable non-words. The phonological loop is highly important in children when learning spoken language, as it is crucial in the building of vocabulary (Alt \& Suddarth, 2012; Baddeley, 2003; Gathercole, 2006; Marchman \& Fernald, 2008). There are examples of individuals lacking the phonological loop due to brain damage, who are unable to learn the new vocabulary of a foreign language, as they are not able to store and form representations of the novel sound combinations (Baddeley, 2003).

Children with severe or profound congenital hearing impairment aided with $\mathrm{HA}$ or $\mathrm{Cl}$ typically display limited phonological WM, while visuo-spatial and complex WM develop to the same capacity as in children with NH (Gathercole, 2006; Lyxell et al., 2013; Peterson et al., 2010). A limited phonological WM may, as explained above, impact development of vocabulary as well as other language skills, such as speech comprehension. Similarly, the development of the visuo-spatial component should be impacted by a severe visual impairment present at birth or acquired early (Bonino et al., 2008; Vecchi et al., 2004b). However, in this case the visuo-spatial component develops to store and process spatial information and the individual's inner imagery of such stimuli, and display a similar capacity as that found in sighted individuals (Bonino et al., 2008; Vecchi et al., 2004a).

\section{Reading skill}

Reading skill is a composite cognitive skill, consisting of the parallel processes decoding and comprehension, which in beginning readers with normal hearing relies heavily on phonological processes. In many languages, speech is translated to visual code by combining symbols (letters) of the individual speech sounds into sequences representing words (Lundberg, 2009; Welcome \& Joanisse, 2012). Because of this nature of texts in western 
societies, a typical method of teaching reading is to emphasize the phonological aspects (Lundberg, 2009). Thus, a common method of reading instruction begins with teaching of the alphabet and establishing phoneme-grapheme connections (speech sounds to their letters), and then move on to instruct on how sequences of letters form words (McGeown, Johnston, \& Medford, 2012; Nakeva Von Mentzer, 2014). However, there are other strategies in teaching reading, for instance, by training broader phonological skills such as rhyming and blending, and instructions guiding the beginning reader to more pragmatic aspects of text, such as word shapes, rather than focusing on phonological decoding (McGeown et al., 2012; Thompson et al., 2009). McGeown et al. (2012), and Thompson et al. (2009) found that different cognitive skills underpinned reading skill, depending on what type of instruction the reader had received.

Another factor which indirectly can influence reading ability, is impairments in hearing (Dillon et al., 2012; Lyxell et al., 2009) or vision (Greaney \& Reason, 1999; Pring, 1994). Learning to read requires an understanding that speech sounds are separate from words and can be structured into infinite combinations (thus forming all words), and that letters and text are representations of language (Nakeva Von Mentzer, 2014). Phonological skills are, therefore, often found to be a strong predictor of reading skill (e.g., Cutting \& Scarborough, 2006; Lederberg et al., 2013; Lundberg, 2009). However, the findings by Wass (2009), Nakeva von Mentzer (2014), Dillon et al. (2012), and Geers et al. (2008) indicate that it is not unusual for children with $\mathrm{Cl}$ in the initial stages of reading acquisition (i.e., in the ages between $6-9$ years) to display similar level of reading comprehension as children with $\mathrm{NH}$, despite displaying poor performance on tasks of phonological processing.

Greaney and Reason (1999) found that children with congenital blindness, who read using the tactile script Braille, displayed better phonological processing than a control group of sighted peers. Despite this, the participating children with blindness displayed poorer reading skill. The findings by Dodd and Conn (2000) were similar with regard to reading comprenhension and decoding in a group of children with blindness. The results from both studies highlight that the poorer reading skills could be due to the complexity of Braille, which contains both symbols for individual speech sounds and contractions of common letter combinations (e.g., 'THE', 'AND') (Dodd \& Conn, 2000; Pring, 1994). Also, the two by three matrix with its miniscule bumps has less salient cues than printed letter, it has to be perceived through a less sensitive sense than vision, and the braille symbols are thus easier to confuse with each other (Dodd \& Conn, 2000; Greaney \& Reason, 1999).

Since individuals with hearing impairment often have difficulties with identification and separation of the smaller phonological units, establishing the grapheme-phoneme (letter to sound) connection can be challenging, and require more effort than for individuals with normal hearing (Nakeva Von Mentzer, 2014). Several studies, for example by Lederberg et al. (2013) and Hermans et al. (2008), have found reading skills to be poor in individuals with profound deafness. This finding is commonly attributed to the fact that individuals with deafness cannot access the phonology of spoken language, but have to rely on an abstract 
understanding of it (Hermans et al., 2008). Also, as sign languages are separate languages from the spoken languages surrounding them, and text is a visual representation of the latter, learning to read often means learning a new language for individuals with profound deafness. However, high level of proficiency in sign language, and good skills in sign language phonology, are predictors of reading skill (Hermans et al., 2008).

As experience in reading accumulates, the reliance on phonological processes declines in the typical reading development (Lundberg, 2009). There are also studies finding that reading in itself improves phonological skill (Blaiklock, 2004). For instance, children who have learnt to read can perform a task of word segmentation (being able to identify and repeat the separate speech sounds that a word consists of), while children with no reading ability perform poorly on segmentation tasks (Blaiklock, 2004). There is an interplay in the development and refinement of cognitive skills underpinning spoken language and reading so that practicing reading for instance leads to an increase in vocabulary, as well as knowledge of what the acquired words look like in print, and this in turns speeds up the reading process (Aguiar \& Brady, 1991; Verhoeven \& Perfetti, 2011). It is, however, possible to be a skilled decoder of text, without being particularly good at understanding the message (Torppa et al., 2007), while others might be good at understanding the gist of a paragraph though not being that skilled decoders of words. Both these components: decoding and comprehension, are necessary in order to make reading effortless and enjoyable (Lundberg, 2009; Welcome \& Joanisse, 2012). Hence, in the present thesis both aspects of reading have been examined.

Society of today is often called 'the information society', and the dissemination of all this information relies heavily on the citizens' ability to read. But more than being informational, reading gives access to fictional worlds, to characters' minds, feelings, and lines of reasoning. There is accumulating research describing how reading helps develop language skills (Hermans et al., 2008; Verhoeven \& Perfetti, 2011), and the ability to understand the thinking and emotions of other persons (Kidd \& Castano, 2013; Mar et al., 2006). This latter ability is central in theory of mind.

\section{Theory of Mind (ToM)}

Theory of Mind (ToM) is highly complex, and dependent on several other complex cognitive skills, such as executive functions (Müller, Liebermann-Finestone, Carpendale, Hammond, \& Bibok, 2012), language proficiency (Slade, 2005), and social cognition (Garfield et al., 2001). Social cognition is a broad concept used to describe the processing, storage, and application of information about other people and social situations, focusing on the role that cognitive processes play in social interactions (Garfield et al., 2001). ToM is a specific, and rather abstract, feature of social cognition, and denotes the ability to impute mental states to self and to others, as is done in order to understand the rationale of the actions and feelings of others (Baron-Cohen et al., 1997; Happé, 1994; Wellman et al., 2011). In other words, ToM is the understanding of why other people act and behave like they do, and not only semantic knowledge from experience of how they generally act. 
Some early social cognitive behaviors have been described as expressions of abilities of specific significance for the later emergence of ToM (De Jaegher et al., 2010; Carpenter et al., 1998). These behaviors include gestures (with the purpose of being communicative), joint attention, and turn taking (Garfield et al., 2001; Carpenter et al., 1998). Deriving from the accounts by Garfield et al. (2001) and Carpenter et al. (1998) gestures can be considered as a type of basic communication and aims at directing another person's attention toward something, such as a need of the gesturer (e.g., signaling 'pick me up' by lifting arms upward, toward a parent), or an external event (by pointing at an object of interest). Gesturing can be the first step in an interaction with joint attention, in which one person directs the attention (i.e., gaze) of another person toward an external event, which they then interact about together (Garfield et al., 2001; Carpenter et al., 1998). Studies investigating the amount of gesturing and turn taking in toddlers have found that these communicative behaviors are predictive of language development (Rowe \& GoldinMeadow, 2009). Also, studies have repeatedly found that individuals who are poor at this basic communication, such as individuals with severe autism spectrum disorder, often display impairments in ToM (Garfield et al., 2001; White et al., 2009).

Another group which can display delays or deviances in achieving this basic communication are children with sensory impairments (Garfield et al., 2001; Minter et al., 1998). Children with visual or hearing impairment can display delayed or deviant development of ToM (Garfield et al., 2001; Minter et al., 1998; Sundqvist et al., 2014). Typically, the explanation of the delayed or deviant development is that sensory impairment, whether auditory or visual, prevents the child from perceiving all information necessary to fully partake in the social interaction, hence missing out on much of the experiences on which development relies (Garfield et al., 2001). There are strong indications that individuals need ample opportunities to interact and socialize with others in order to develop ToM to full and nuanced extent (Lewis et al., 1996; Garfield et al., 2001). As stated previously, there are correlations between language proficiency and ToM (Schick et al., 2007; Garfield et al., 2001; Slade, 2005). Possibly, in the case of children with sensory impairments the lack of experience in communication and interaction, due to the impairments, could lead to poorer language development, which in turn could be a causative factor in the delay of development of ToM. The findings by Schick et al. (2007) of equal levels of ToM in children with $\mathrm{NH}$ and spoken language as in a group of children with profound deafness in families fluent in American Sign Language could be seen as a clear indication of the close relationship between language skills and ToM. The finding by Sundqvist et al. (2014), that children with early $\mathrm{Cl}$ implantation (before 2 years of age) displayed very little or no delay of development of ToM, can be seen as further support of this line of reasoning, as these children have early access to spoken language and may develop spoken language skills in a more typical way. One aspect, which has not been focused in research, is whether ToM would decline in adults as a result of acquired, long-term sensory impairment. However, in the case of adults with USH 2 the hearing impairment has been present since birth, but the visual impairment comes progressively. This situation of course poses a problem in 
discerning whether a different level of ToM in the group could be explained by delayed or deviant development due to the $\mathrm{HI}$, or whether it could be an effect of long-term visual loss. As there was no previous knowledge about ToM in the group with USH2, this was one of the areas explored in the present thesis.

In sum, the views on the development of ToM could be considered to be in line with both a biological perspective of impairment and brain plasticity (amount and quality of stimuli affects the brain, and lack of stimuli has cascading effects), and a more psycho-social view, where the lack of interaction could be attributed to the individual's and the surrounding's inability to compensate (i.e., by applying other cognitive skills or by adapted communication strategies).

ToM in adults is typically investigated only when there are indications of that the ability would be impaired, such as when specific regions of the brain has suffered damage, or when a diagnosis in the autism spectrum is suspected (Apperly et al., 2009; Jolliffe \& Baron-Cohen, 1999). Happé (1994) developed an advanced test of ToM in order to investigate and describe the degree of impairment in ToM displayed by a subgroup of individuals with autism spectrum disorder, who performed within the norms of available tests, but could not function typically in social situations. The Strange Stories test aims at being naturalistic, and resembles complex everyday social situations by embedding the ToM task in a context, such that induction and attribution of mental states are needed in order to answer the problem (Happé, 1994). The stories with ToM content require understanding of common types of motivations, that can lie behind utterances, and include understanding of lying, white lies, joking, pretending, misunderstanding, appearance/reality, sarcasm, figure of speech, double bluff, and contrary emotions (Happé, 1994). The test relies heavily on speech comprehension, however. In order to avoid misinterpretation of a person's performance on ToM, there is a set of stories with equivalent complexity, but without the ToM content. Should the participant perform poorly on the stories without ToM content, then language skills could be an issue, and performance on the ToM-stories needs to be interpreted with care. A common pattern of performance in individuals with autism spectrum disorder is performance at level with individuals without the diagnosis on the stories without ToMcontent, while performing significantly below on the ToM-stories in terms of poorly motivated answers, which do not reflect the mental states of the story's characters (Happé, 1994; Baron-Cohen et al., 1997; White et al., 2009). 


\section{The Empirical Studies}

\section{General Aims}

Increased knowledge about cognitive performance in individuals with the combination of visual and hearing loss, and specifically in the group with USH, could be useful in the design of rehabilitation services and interventions. There are some established rehabilitative services for persons with deafblindness in Sweden. However, these organizations have long been aware that the interventions and services they offer, regarding for example communication strategies, are based on clinical experience and typically not on systematized, empirical research findings. Research, such as the present, represents an attempt to describe the group in a systematized way, and to generate empirical findings on which fine-tuned interventions can be built.

Thus, an overarching aim of the thesis was to investigate the impact of the development of combined visual and hearing loss, deafblindness, on cognitive performance. In order to study this, a specific diagnosis causing deafblindness was selected, and children as well as adults with Usher Syndrome were included in the research. There were several reasons for investigating the impact of deafblindness through USH. Primarily, this syndrome is well researched with respect to other aspects than cognitive, such as genetic (i.e., Cremers et al., 2007; Kremer et al., 2006) and medical (Sadeghi et al., 2004a; Sadeghi et al., 2004b; Möller, 2007) conditions. Findings by, for example, Boëda et al. (2002), and Kremer et al. (2006), point in the direction of that the expression of the USH mutations are isolated to the functions of the ear and the eye, indicating that if the group would perform differently on cognitive measures, this would likely be an effect of the sensory losses.

\section{Specific Aims}

To describe level and expression of the specified cognitive abilities in individuals with Usher syndrome type 1 and 2, in order to begin the development of new knowledge in this area, the studies of the thesis aimed to develop knowledge through the following specified objectives:

- To examine the level of development of phonological and lexical skills, and working memory capacity (WMC), in a population of children with Usher type 1 using $\mathrm{Cl}$ (Study I).

- To explore and describe reading ability in five children with $\mathrm{USH} 1+\mathrm{Cl}$ in comparison to three control groups: children with normal hearing $(\mathrm{NH})$, children with hearing impairment and hearing aids $(\mathrm{HI}+\mathrm{HA})$, and children with other type of deafness and $\mathrm{Cl}$ (Other $\mathrm{Cl}$ ). Also, the relationships between reading ability, WM, and phonological and lexical skills were described in the individual children with $\mathrm{USH} 1+\mathrm{Cl}$, in order to further explore strategies underlying reading skill (Study II).

- To investigate working memory, phonological skills, lexical skills, and reading comprehension, and to compare the performance of the group of adults with USH2 to that of a matched control group with normal hearing and vision (Study III). 
- To investigate ToM in two groups of adults with deafblindness: one with USH2 and another with AS (Study IV).

\section{Method}

\section{Methodological Challenges and Considerations}

\section{Ethical considerations}

Usher syndrome is a rare condition, and as Sweden is a country with a relatively small population the consequence is that the total group of individuals known to have USH in Sweden is only about 700 persons (Socialstyrelsen, 2014). A limited and distinct population presents several ethical problems for researchers. One issue is the conflict between the need to publish information on participants in order to increase interpretation and understanding of findings, and the need to limit this information in order to protect individuals' integrity. Many of the persons with USH in Sweden are active members in society and are well known in their communities. Commonly there is a score of health professionals around a person with USH, and because many individuals with USH are also highly motivated to help expand knowledge about the syndrome, several have contacts within research environments. Hence, publishing detailed information on each individual could potentially lead to identification of the person by people outside the research group. This could be particularly disagreeable if each individual were to be discussed in relation to her or his performance on the experimental tests. It would also be potentially disturbing and unpleasant for the person to be able to identify her/himself, as opportunity to discuss the implications and interpretations with each participant would be limited. It would also be slightly inappropriate in the case of the present thesis, as the tests used were not intended for clinical application or interpretation on an individual level. Therefore, detailed case studies are not suitable from an ethical point of view. The present thesis was confronted with these conflicts of protection of integrity, and potential access to information, repeatedly in the process of interpreting and publishing the findings in the different studies. These ethical issues were dealt with in a number of compromises between the need to present information, data, and interpretations, and the need to protect the integrity of the participants. One such compromise is the analysis of number of participants with a score (RT) above or below the mean or median value of the control groups, and qualitative analyses of whether or not there existed a pattern in the participants' performances (i.e., Study II and III where it is investigated whether individuals with low scores on reading also performed poorly on phonological measures). Another solution was to present the demographic data on group level as much as possible when it concerned the adults. Unfortunately, this was not a useful way to present the demographics on the children with USH1, and instead the amount of demographic information presented was as limited as possible for each participant.

Another ethical issue in performing research with a discrete population like USH is the risk of exploitation of the group. There might be great interest in investigating aspects of the population, for instance, in order to investigate the stability of developed models in a 
variety of research areas (e.g., medicine and treatments, genetics, cognitive psychology, etc.), as well as in order to gain knowledge useful for the professionals working with individuals with USH, and for members of the group. This interest could, quite unintentionally, create a sense of exposure and stigmatization in the group. It could also lead to fatigue with continuous requests from research projects, and decrease motivation to participate. Thus, it is important for researchers to coordinate their projects when possible, so as to limit the number of occasions for data collections, to be very careful in selecting tests and instruments in order to maximize outcome of testing, and to limit the mental strain on participants. The present thesis was developed in a research group with several other (mutually independent) projects also investigating populations with deafblindness. As a result, the data collection with the adult group with USH2 could be performed jointly with one of these projects, and a weekend event could be created, which was appreciated by the participants as they got the opportunity to meet and discuss together as well as participate in the studies.

\section{Design and data collection}

The total number of potential participants meeting the inclusion criteria for the present thesis regarding age and primary language was quite low, and hence the two groups of participating children and adults represent a respectable proportion of the population available for participation. The limited number of available participants severely restricts the options of design of the study, as conventional statistical methods typically require larger numbers for the demands on reliability to be met. Despite this, the research is valuable and contributes with novel information about the group, even though the volume of data is slight, making generalizations difficult. As the need for more knowledge on the conditions for and in individuals with USH is substantial, research studies are necessary and hence have to deal with the methodological issues that are inherent in research with small groups.

When presenting participants to a number of cognitive tests in one session, there have to be tradeoffs and compromises, or the test session would be too demanding, which would compromise the quality of data. In the case of the children the research question focused on one composite skill, namely reading, using two tests to examine this skill. Children in general have less endurance with cognitive tasks than adults, and hence greater care has to be taken in choosing what tasks to include during a session. During the test sessions of the studies in the present thesis, the participants with $\mathrm{HI}$ really strained themselves in order to deal with tasks specifically difficult for them, as a majority of the tests dealt with language sounds. There were, of course, technological devices available to the participants for reinforcement of the auditory stimuli, and mentions of poor audibility were rare, though several of the participants voiced feeling weary after performing several tests taxing phonological and lexical skills. The older children might also have begun to experience some visual problems (e.g., poorer contrast sensitivity), and in the adult group the vast majority had to exert some effort in attaining all visual information necessary, thus, further adding to the mental load during testing. Despite these potential drains of energy, several of the adult 
participants exclaimed that they felt less tired than they had expected to, and also commented that the steps taken to increase visibility of test stimuli were adequate and helpful.

The number of tests of phonological skills and lexical skills was different for the children with USH1+ $\mathrm{Cl}$ and the adults with USH2. As previously stated, the tests rely on the same theoretical framework, though the tests for children are adapted to fit and display development of the ability, in that they can start from a more basic level of skills and have a wider range of tasks to fit children of different ages. Also, since the abilities are under development in children it is more important to capture the different aspects of phonological processing as it might develop differently in individuals. Hence, there were three tests of each set of skills, taking into account different aspects. In adults the process of development is stabilized to a higher degree, and a single, more extensive and demanding measure, such as Rhyme Judgment, can be sufficient to adequately measure an adult's phonological skill. However, as spoken communication is also highly reliant on working memory, and, in particular, on automatic binding in the episodic buffer of sensory input to long-term memory representations (Rönnberg et al., 2010), a measure of phonological WM was also considered necessary in order to properly describe the adult groups.

A strength of the thesis is that it focuses on individuals with a very specific disability, i.e., USH1 or 2. Typically, there is great heterogeneity in small populations with only one specific trait, such as, hearing with a $\mathrm{Cl}$, in common. The diagnosis of all participants with USH in the present thesis was well investigated and secure. In the case of the adults with USH2, they all had the same genetic mutation, i.e., USH2a. Even though the heterogeneity within the groups was quite large, on this aspect they were as homogeneous as possible. This could be argued to slightly increase the likelihood of the groups' performances on the tests being impacted by the sensory impairments resulting from the syndrome, rather than by other, random factors.

\section{General procedure}

In all four studies, data were collected on one occasion, during which the participant performed a battery of cognitive tests. In order to avoid issues with feelings of insecurity or stress in a new situation, the children were seen either in their school or in their home, and if the child so whished with a parent or assistant present. The test session with the children lasted for 1.5-2 hours, during which short breaks were offered between each completed test. A longer break was taken when half of the tests had been completed. The sessions were held in quiet rooms with good light conditions. All the tests of phonological skills, lexical skills, and working memory were presented using a laptop computer. The stimuli were, for the most part, auditory, with recordings of a female speaker presenting words or non-words. The children responded either by pushing the spacebar when target stimuli had been identified, in which case both reaction time and accuracy were recorded, or by giving the answer verbally, in which case the responses were recorded for correction. The tests of reading skill were administered on paper. Answers were verbal and recorded for scoring, 
which was done by students on the program of speech and language pathology, who had experience from their training to transcribe and correct voice recordings. The children in the control groups were tested under similar conditions and with the same routine as the children with USH1+Cl (for a detailed description, see Wass, 2009).

During a two-day event with persons with USH2 the adult participants were seen for sessions of two hours per person. The participants also had their audiograms taken during the event. The five test instructors for the sessions of cognitive testing had been trained on the specific tests, informed about the conditions of persons with a combination of visual and hearing impairment, and several of the test instructors had experiences of working with individuals with deafblindness. During the test sessions, aids for vision and hearing were available. The visual aids consisted mainly of options of different settings for the tests displayed on a computer, such as bigger font size, or other contrasts (background and letter coloring), to fit the participant. All participants with USH2 chose the highest contrast setting, which is orange-yellow text on black background. To reinforce auditory stimuli and the test instructor's voice there were FM-systems available, as well as loudspeakers.

The matched, adult participants with NHV were seen for testing at either the Audiological Research Centre in Örebro, or at the Department of Behavioral Sciences and Learning at Linköping University. All participants of the control group had their audiograms taken in order to ensure that they were indeed of normal hearing. Visual status was not checked, but none of the participants reported having any issues with vision. These participants also performed the visually displayed tests in the setting with highest contrast.

\section{Tests}

See table 1 for an overview of the tests used in the studies of the thesis.

\section{General cognitive ability}

All participating children performed the test Block Design from the Wechsler Intelligence Scales for Children (WISC-III). Block Design is a well-established clinical measure and has strong correlations with problem solving, mental flexibility, and general cognitive ability (Shelton et al., 2009). In order to be included for participation, performance on Block Design had to be within the norm value of the child's age group. A similar test of general cognitive ability was not considered necessary for the adult group as all circumstances around the participants indicated that all would perform within the expected norm value for their age. However, the group of adults performed a test of visual decision-making, Physical Matching, as a control measure to ensure that instructions were understood and followed, and to familiarize participants with the test procedure.

\section{Verbal ability}

The adult groups performed the test of Antonyms as an indication of their verbal ability (. The task is to correctly identify the pairs of antonyms among the five words of each item in five minutes. The test has been used repeatedly for the purpose of estimating level of verbal ability in participants in different projects (Lyxell et al., 1996; 1998). 
Regarding the children there was no general measure of verbal ability, but instead the studies aimed at describing the basic processes and skills underpinning this ability.

\section{Phonological skills and Phonological Working Memory}

Phonological skills in the children were measured by three tests, each designed to measure a different aspect of phonological skills. The tests have been developed by Wass et al. (2009) in accordance with the cognitive theories on phonological processing. The test Nonword Discrimination measures the ability to discriminate between speech sounds, and the task was for the participant to press the space bar if the presented pair out of 16 non-words was identical. In order to achieve maximum score (8) on the test, the participant had to discriminate all pairs correctly, same and different (i.e., push when identical and not push space bar when pairs were different). In contrast, real words were used in the test Phonological Representations, in which the participant was asked to report when a familiar word was pronounced correctly out of several options. To make certain that the participant was familiar with the word s/he was shown an illustration of the word (i.e., "sofa") and asked to say what was depicted. The task in Phoneme identification was to press a button if there was a specific language sound within the auditorily presented non-words (i.e., "is there an ' $r$ ' in 'federur'?" or "is there an ' $s$ ' in 'höntpule'?").

The items of the measure of phonological skill for the adults were embedded in a visually displayed text on a computer screen. The test has been developed by Lyxell et al. (1996) in accordance with cognitive theories on phonological processing. The task was to identify the pairs of words that rhymed, regardless of how the words were spelled or what font size was used. This task taxes phonological long-term representations of speech sound.

Among the children, phonWM was measured with two tests, loading on the storage and the rehearsal component of phonWM. In the test Non-Word repetition participants were asked to repeat back non-words of increasing syllable length, thus giving opportunity to use suprasegmental cues as well as chunking. In Serial Recall of Non-words the task was to repeat back increasing series of one-syllable non-words, which taxes the storage of the phonological loop to a higher degree and is more sensitive to blending and intrusion. This test was also used among the adults to measure phonWM. The verbally repeated items were recorded on the test occasion and scored off-line for percent consonants correctly reproduced (p.corr.c).

\section{Lexical skills}

There were three measures of lexical skill for the children, all of which has been developed by Wass et al. (2009) in accordance with theories on lexical processing. In all three tests the target words are real words. In word-spotting the participant was asked to push a button as soon as $\mathrm{s} /$ he identified the real word among series of one-syllable non-words. In Semantic Decision making the participant's task was to push a button when there was a word adhering to a specific, defined category (i.e., "push the button when you hear something that is an animal"). The task in Picture Matching was to identify the correct picture among 
four alternatives after a word had been presented. The incorrect alternatives were semantically similar, phonologically similar, or unrelated.

The lexical test for adults has been developed by Lyxell et al. (1996) in accordance with theories on lexical processing. The items were presented visually and the task was to push a button corresponding to 'yes' for the real words displayed, and 'no' when the item was not a word.

\section{Working memory}

The measures used with the participating children and adults were based on the same theoretical construct and resemble each other. Both tests contain a part where the presented material has to be processed, and then stored, in order for the task to be completed. For children the items were presented in auditory modality, and the first task was to complete each sentence. The number of sentences in each sequence increased from two up to five, and after each sequence was completed, the target task was to recall the words that had been filled in. For adults, the test was presented as text on screen and instead of completing sentences, the task was to judge whether each sentence of three words was semantically bizarre or not. The participant did not know beforehand whether she or he would be asked to recall the first or last words of the sentences in the latest sequence. The sequence length began at two and increased up to seven. Participants were allowed to discontinue at any time, and the test was aborted if the participant failed to recall the words of a sequence on the two attempts offered at that level.

The children also performed a test of visuo-spatial WM, in order to have a measure independent of auditory processing and verbal ability. In the test Matrices a matrix of $5 \times 5$ squares of grey color were displayed on a computer screen. During the test, a set number of squares turned black for a short period of time, after which they went back to grey. The task was for the participant to click on the squares that momentarily had turned black. The number of black squares started at two, and increased every third trial up to eight. The test was aborted if the participant failed on two of the three attempts of a task.

\section{Reading skill}

The children performed a test of decoding skill, i.e., Towre. The test consists of two lists of non-words and two lists or real words. The test has been used in many research projects, but has not been evaluated for Swedish conditions; it also has some issues, as the lists are not very balanced with regard to number of weirdly spelled sounds and combined sounds. However, the test gives a reasonable indication of the efficiency of decoding, and can be further analyzed to give insights on strategies (Furnes \& Samuelsson, 2011).

Different tests were used for measuring reading comprehension. The children were tested with Woodcock reading test, in which the task is to complete sentences of increasing complexity, while the adults performed the Gates MacGinitie test of reading comprehension. The adults read paragraphs of increasing length and complexity, and then responded to multiple questions about the explicit or implicit content of the text. 


\section{Theory of Mind}

The Strange Stories test developed by Happé (1994) was performed only by the adult participants. There are three parts to the test and these parts measure different aspects of cognitive abilities. The Jumbled Sentences measure participants' ability to store and recall verbal information. The Physical Stories measure participants' verbal reasoning skills on a problem of logical type. The stories with ToM content measure participants' ability to understand social content and understand the motives, rationales and feelings behind other persons' behavior. 


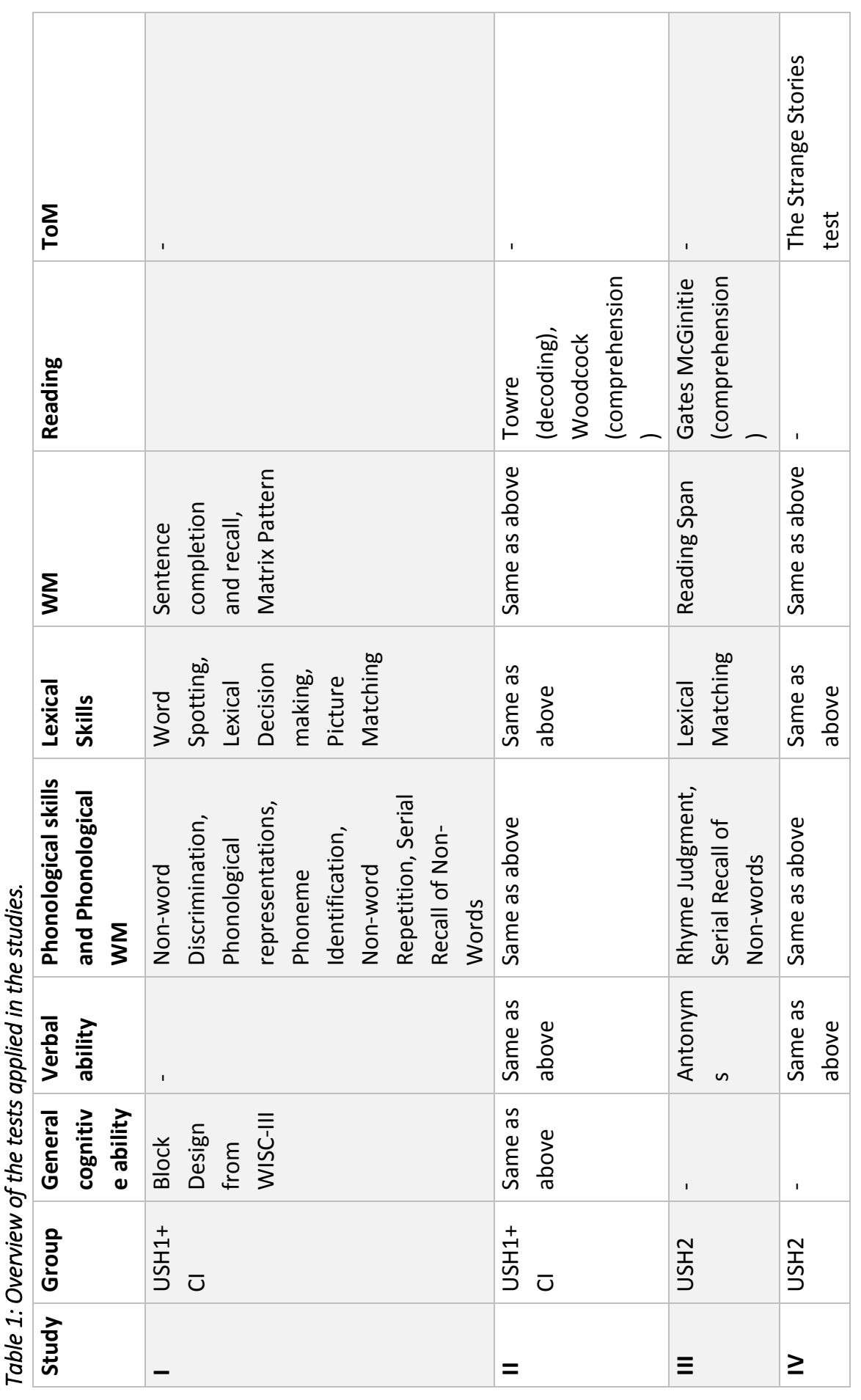




\section{Measures}

Hearing impairment is in this work defined in accordance with WHO guidelines in which $\mathrm{HI}$ is measured as the best ear pure tone average hearing over four frequencies (PTA4): $500 \mathrm{~Hz}$, $1000 \mathrm{~Hz}, 2000 \mathrm{~Hz}$, and $4000 \mathrm{~Hz}$. The WHO guidelines state four grades of HI: 1 = mild, PTA4 26-40 dBHL; 2 = moderate, PTA4 41-60 dBHL; 3 = severe, $61-80 \mathrm{dBHL}$; and 4 = profound, PTA4 > $81 \mathrm{dBHL}$. Throughout this thesis degree of hearing impairment will be reported either using the WHO scale, or by presenting the actual PTA4 value.

Visual acuity is measured according to common standards by using Snellen charts. They are reported in the decimal scale, where a value of 1-0.6 is considered normal vision, and 0.05 indicates functional blindness. The visual field of the adult participants with USH2 and AS, respectively, is reported as kinetic visual field data (Goldman perimetry). A classification by Grover (1997) was used where the visual field data were categorized into one of five field phenotypes:

Phenotype 1: normal visual field

Phenotype 2: presence of a partial or complete ring scotoma, the latter either extending or not extending into periphery.

Phenotype 3: Concentric central field loss with a remaining peripheral island, less than onehalf of the field circumference

Phenotype 4: Marked concentric loss (< 10 degrees)

Phenotype 5: no visual field at all (blind).

\section{Participants}

The Swedish database (managed by the Audiological Research Centre of Örebro University Hospital) on persons with Usher syndrome was used in order to locate potential participants for the studies in this thesis. Each person in the database has given written consent to the information about them being stored there, that it is used in research, and to being contacted about participation in studies via the database. Recruitment was done on two separate occasions; in order to recruit children with USH1+CI for participation in Studies I and II, and when adult participants with USH2 where recruited for participation in Studies III and IV. Potential participants with USH1 and their parents were also contacted through the interest organization Barnplantorna, for families with children with cochlear implants or hearing aids. Information about the participants' visual and hearing status was retrieved from the database.

Letters of information directed to both the parents and the children were sent to all individuals with $\mathrm{USH} 1+\mathrm{Cl}$ in the database in the age-range 7-16 years. Six children with USH1+Cl agreed to participate, with their parents' consent, and the data for a seventh child were retrieved from a data collection done by Wass (2009) using the same tests and methods as in the present thesis. Demographic data on the children with $\mathrm{USH} 1+\mathrm{Cl}$ can be found in table 2 . 
Table 2: Demographics of the participants with Usher syndrome type 1.

\begin{tabular}{|l|l|l|l|l|l|}
\hline Participant & Age (y:mo) & $\begin{array}{l}\text { Age at 1st } \\
\text { CI }\end{array}$ & $\begin{array}{l}\text { Age at 2nd } \\
\text { CI }\end{array}$ & Language & Bilateral \\
\hline $\mathbf{1}$ & $7: 6$ & 20 months & 22 months & Spoken Sw. & Yes \\
\hline $\mathbf{2}$ & $8: 0$ & 18 months & 30 months & Spoken Sw. & Yes \\
\hline $\mathbf{3}$ & $8: 1$ & 12 months & 30 months & Spoken Sw. & Yes \\
\hline $\mathbf{4}$ & $8: 10$ & 9,5 months & 18 months & Spoken Sw. & Yes \\
\hline $\mathbf{5}$ & $12: 4$ & 39 months & - & $\begin{array}{l}\text { Sign } \\
\text { supported } \\
\text { Sw. }\end{array}$ & No \\
\hline $\mathbf{6}$ & & & & Spoken Sw. & Yes \\
\hline $\mathbf{7}$ & & & & SSL/spoken & Yes \\
\hline
\end{tabular}

SSL: Swedish Sign Language

The performance of the children with USH1+Cl was put in relation to that of three control groups. Except for the data from 10 children with normal hearing $(\mathrm{NH})$, which were collected by me, all data on control groups had been collected in a previous research project by Wass (2009). The groups consisted of children with NH in the ages 7-12 years, children with hearing impairment and hearing aids $(\mathrm{HI}+\mathrm{HA})$ in the ages of 7-12 years, and children with deafness, due to other causes than USH1, and $\mathrm{Cl}$ (ControlCI) in the ages 7-14 years (See Table 3).

The number of children in the control groups with $\mathrm{NH}$ and $\mathrm{Cl}$, respectively, vary over the different tests. In the case of children with NH the tests Phonological Representations, and Phoneme Discrimination (phonological skills) only have 46 participants. This is because children with $\mathrm{NH}$ above the age of eight years performed at ceiling on these tests, and hence further collection of data on these measures was not considered meaningful. In the case of the control group with $\mathrm{Cl}$, also collected by Wass, many children with $\mathrm{Cl}$ chose to decline, or did not finish all tests of phonological skill. Probably the children who declined, or did not finish, found the tests tiring, too difficult, or were not motivated to participate. Also, in the studies by Wass, the tests of reading comprehension were only introduced after half of the data from the different groups had been collected. 
Table 3: Demographic data on the control groups in Studies I and II.

\begin{tabular}{|l|l|l|l|l|l|}
\hline $\begin{array}{l}\text { Control } \\
\text { Group }\end{array}$ & $\begin{array}{l}\text { Mean age } \\
(y: m o)\end{array}$ & $\begin{array}{l}\text { Age SD } \\
(\text { y:mo })\end{array}$ & $\begin{array}{l}\text { Range } \\
(y: m o)\end{array}$ & $\begin{array}{l}\text { Mean age at } \\
\text { diagnosis }\end{array}$ & $\begin{array}{l}\text { Mean age at } \\
\text { intervention } \\
\text { (HA or CI })\end{array}$ \\
\hline $\begin{array}{l}\text { Children with } \\
\text { NH } \\
\boldsymbol{n}=\mathbf{1 2 0}\end{array}$ & $9: 3$ & $1: 8$ & $6: 8$ & - & - \\
\hline $\begin{array}{l}\text { Children with } \\
\text { HI+HA } \\
\boldsymbol{n}=\mathbf{4 3}\end{array}$ & $9: 3$ & $1: 9$ & $6: 6$ & $\begin{array}{l}\text { Not } \\
\text { available }\end{array}$ & $3: 3$ \\
\hline $\begin{array}{l}\text { Children with } \\
\text { CI } \\
n=33\end{array}$ & $8: 11$ & 2 & $7: 9$ & $1: 2$ & $3: 5$ \\
\hline
\end{tabular}

Letters of information were similarly sent to all adults with USH2a within the age-range 1865 years, registered in the database on USH, at the time this group consisted of 37 persons. The 'a' following USH2 implies a specific genetic locus of the mutation causing the characteristic symptoms of USH2. This specification of inclusion criteria was chosen as USH2a is the most common of the USH2 variants in Sweden, but also in order to make the group slightly more homogeneous. Fourteen adults consented to participation in the study, though thirteen remained for the analysis as one individual was excluded because of issues with language comprehension during the test session. The participant who was excluded did not have Swedish as primary language, and in the testing situation it became evident that this impacted performance to a high degree on all tests. To include this participant would hence have biased the data, and the subsequent analyses.

The adult participants with USH2 were matched as regards age and educational level to persons with normal hearing and vision (NHV). These participants were recruited by a research assistant (Jennie Hjaldahl) and by the PhD student in the thesis project (me), and performed the tests at either the Audiological Research Centre in Örebro, or the Department of Behavioral Sciences and Learning in Linköping. Fifteen persons were given letters of information regarding participation in the control group with $\mathrm{NVH}$, and 10 persons consented to participate in the study. Six of these were tested in Örebro, and four in Linköping, by one of the two experienced test instructors. Demographic variables for the group of adults with USH2 and their matched controls are reported in Table 4. 
Table 4: Data on age, hearing thresholds (PTA4) and vision for the adult participants. Visual field reported according to the Goldman perimetry, where a classification of $1=$ normal visual field and $5=$ no visual field. Visual acuity reported in the decimal scale, where $1=$ normal acuity and $0.0=$ blindness. NV = Normal Vision

\begin{tabular}{|l|l|l|}
\hline & $\begin{array}{l}\text { USH2, } \mathbf{M} \text { (SD) } \\
\mathbf{n}=13\end{array}$ & $\begin{array}{l}\text { Control, M (SD) } \\
\mathbf{n = 1 0}\end{array}$ \\
\hline Age & $38.8(12.7)$ & $38.4(11.0)$ \\
\hline PTA4 Left ear & $66.2(11.6)$ & $3.7(5.1)$ \\
\hline PTA4 Right ear & $67.5(13.3)$ & $3.3(3.6)$ \\
\hline Visual Field, Left & $\begin{array}{l}3(1.2) \\
\text { min-max: } 1-5\end{array}$ & NV \\
\hline Visual Field, Right & $\begin{array}{l}3(1.1) \\
\text { min-max: } 1-4\end{array}$ & NV \\
\hline Visual Acuity, Left & $\begin{array}{l}0.47(0.37) \\
\text { min-max: } 1-0.05\end{array}$ & NV \\
\hline Visual Acuity, Right & $\begin{array}{l}0.41(0.35) \\
\text { min-max: } 1-0.05\end{array}$ & NV \\
\hline
\end{tabular}

\section{Levels of Analysis}

Since the overarching aim of the present thesis was to describe specific cognitive skills in the groups with USH, the performance of the participants with USH has been positioned in relation to other populations, by means of group comparisons. Additionally, the studies report on individual performances and present descriptions on how individuals performed in relation to the control groups, in order to nuance the picture and describe the variations in the group. Qualitative observations, such as comments or descriptions of what testing was like for the participants, have been included to some extent primarily into the discussion in all studies, in order to further describe the performance of the groups with USH.

In Studies I and II the group comparisons were made using confidence intervals on the $95 \%$ level ( $\mathrm{Cl95}$ ). This method was deemed to be more robust in regard to the small number of participants and to the differences in variance between groups, than the more commonly used $t$ test. In Study I, in addition to the comparisons of $\mathrm{Cl95}$, regression lines were calculated for the three control groups, with confidence intervals of $95 \%$. The performance of each participant with $\mathrm{USH} 1+\mathrm{Cl}$ on each test was displayed in relation to the regression lines of the control groups. This was done in order to display how the individuals with $\mathrm{USH} 1+\mathrm{Cl}$ each performed in relation to the control groups. In study II another approach was taken and individual performance of the children with $\mathrm{USH} 1+\mathrm{Cl}$ was reported in relation to the performance of the control groups, as well as group comparisons. This was done in 
order to maximize the information provided by the limited amount of data when describing the performance in individuals with $\mathrm{USH} 1+\mathrm{Cl}$.

For Studies III and IV non-parametric statistical methods were applied, as data were not normally distributed, and variance differed too much between the groups. In Study III the Mann-Whitney $U$ test was applied to check for group differences in the distribution of data on the different cognitive tests. Number of individuals with USH2 performing above or below the control group's median value on each test was also reported, in order to further describe the performance of the group with USH2. In Study IV a Kruskal-Wallis analysis was applied in order to capture between-group differences as well as within-group differences in performance on the different tests. Significant findings in the Kruskal-Wallis were followed up with Mann-Whitney $U$ test with Bonferroni correction. Non-parametric correlations (Spearman Rho) were also computed in order to understand whether performance on the test of ToM correlated with performance on other tests or measures. In order to further investigate what could affect performance on the test of ToM, individuals with deafblindness (USH2 and AS) were divided into two subgroups with respect to score on the test of ToM. Individuals performing below the median value of the control group with $\mathrm{NH}$ constituted one group, and those performing at or above the median value another. MannWhitney $U$ tests were applied in order to check for significant differences between the subgroups on the other cognitive measures, and Spearman correlations were computed in order to see if correlations differed between tests and measures in the sub-groups. 
Tablel 5: Overview of the studies' methodology

\begin{tabular}{|c|c|c|c|c|c|}
\hline Study & $\begin{array}{l}\text { Study } \\
\text { population }\end{array}$ & $\begin{array}{l}\text { Control } \\
\text { groups }\end{array}$ & Design & Materials & Analysis \\
\hline I & $\begin{array}{l}\mathrm{USH} 1+\mathrm{Cl} \\
\text { (children) }\end{array}$ & $\begin{array}{l}\text { Control Cl, } \\
\mathrm{HI}+\mathrm{HA}, \mathrm{NH}\end{array}$ & $\begin{array}{l}\text { Group } \\
\text { comparison } \\
\text { s, } \\
\text { descriptive }\end{array}$ & Cognitive test & $\begin{array}{l}\text { Parametric: } \\
\text { comparisons of } \mathrm{Cl} 95 . \\
\text { Performance of the } \\
\text { children with } \\
\text { USH } 1+\mathrm{Cl} \text { described in } \\
\text { relation to regression } \\
\text { lines of control } \\
\text { groups' performance }\end{array}$ \\
\hline II & $\begin{array}{l}\text { USH1+Cl } \\
\text { (children) }\end{array}$ & $\begin{array}{l}\text { Control Cl, } \\
\mathrm{HI}+\mathrm{HA}, \mathrm{NH}\end{array}$ & $\begin{array}{l}\text { Group } \\
\text { comparison } \\
\text { s, } \\
\text { descriptive }\end{array}$ & $\begin{array}{l}\text { Test of reading } \\
\text { skill, cognitive } \\
\text { tests }\end{array}$ & $\begin{array}{l}\text { Parametric: } \\
\text { comparisons of Cl95. } \\
\text { Descriptions of } \\
\text { individual } \\
\text { performance }\end{array}$ \\
\hline III & USH2 (adults) & $\mathrm{NH}$ & $\begin{array}{l}\text { Group } \\
\text { comparison }\end{array}$ & Cognitive tests & $\begin{array}{l}\text { Non-parametric: } \\
\text { Mann-Whitney } U\end{array}$ \\
\hline IV & USH2 (adults) & $\mathrm{NH}, \mathrm{AS}$ & $\begin{array}{l}\text { Group } \\
\text { comparison } \\
\text { s }\end{array}$ & $\begin{array}{l}\text { Test of ToM, } \\
\text { cognitive tests }\end{array}$ & $\begin{array}{l}\text { Non-parametric: } \\
\text { Kruskal-Wallis, Mann- } \\
\text { Whitney } U\end{array}$ \\
\hline
\end{tabular}

\section{Summary of the Papers}

Paper I.

The aim of this study was to examine three basic cognitive skills in children with USH1+Cl. The skills of interest; phonological skill, lexical skill, and working memory (WM), are central in the development of other complex skills, such as reading and speech comprehension. The development of these skills is impacted by deteriorated auditory input, such as the signal received by the brain from a $\mathrm{Cl}$ (Lederberg et al., 2013; Spencer \& Tomblin, 2009; Peterson et al., 2010; Lyxell et al., 2013; Löfkvist et al., 2014). Seven children in the ages 7-16 years participated in the study. Each was seen during a session of two hours of cognitive testing. The cognitive test battery developed by Wass et al. (2009) was selected as it had been evaluated and used among children with speech and language impairment, children with hearing impairment using hearing aids, children with $\mathrm{Cl}$ :s, as well as children with $\mathrm{NH}$. The performance of the group with $\mathrm{USH} 1+\mathrm{Cl}$ was compared to previously collected data on the performance of children with $\mathrm{NH}$, children with hearing impairment and hearing aids $(\mathrm{HI}+\mathrm{HA})$, and children with other types of deafness and $\mathrm{Cl}$ (controlCl). The main finding was that the children with $\mathrm{USH} 1+\mathrm{Cl}$ performed significantly better than the controlCl on one of the cognitive measures, i.e., phonological discrimination (See Figure 1), and that the majority of children with USH1+CI performed above the confidence interval of the controlCI 
on a measure of phonological skill, i.e., non-word repetition (See Figure 3). Another finding was that the three youngest participants with $\mathrm{USH} 1+\mathrm{Cl}$ performed at level with the control group with $\mathrm{NH}$ on the majority of cognitive measures, the exceptions being the two measures of phonological WM (serial recall of non-words and non-word repetition). Two children with $\mathrm{USH} 1+\mathrm{Cl}$ performed at level with the children with $\mathrm{HI}+\mathrm{HA}$, while the two oldest for the most part performed at level with the controlCl. The discussion of the findings focused on that the higher performance in phonological skill on group level could be an effect of the awareness that these children will lose vision over time, and hence become more dependent on their Cls. Hence, it is possible that more effort than is common is invested in teaching these children to use their $\mathrm{Cls}$ to their most. A speculation was also that, due to the nature of the deafness in USH1, the tip-links are malfunctioning on otherwise whole inner hair cells, and that this could be a beneficial condition for the implantation with $\mathrm{Cl}$.

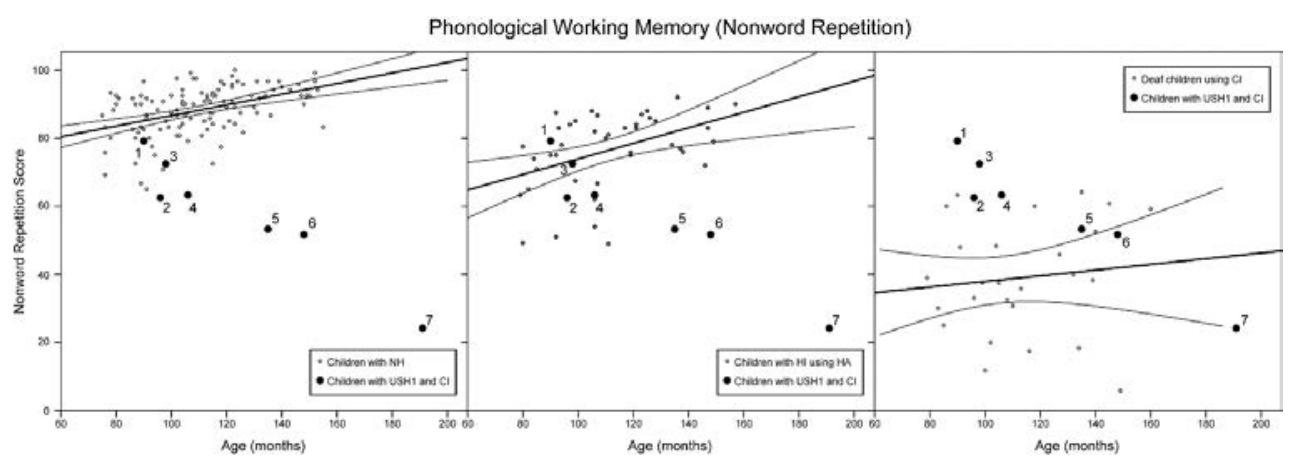

Figure 3: Non-word Repetition. The group with USH1+Cl performs above the control group with $\mathrm{Cl}$. Two of the younger children perform similar to the control group with $\mathrm{HI}+\mathrm{HA}$. 
Paper II.

The aim of this study was to examine reading skills in children with USH $1+\mathrm{Cl}$. Historically, children with deafness have shown low levels of reading skill, but this has changed with the introduction of $\mathrm{Cl}$. Children with $\mathrm{Cl}$ develop the basic cognitive and language skills that are typically involved in reading development in children with $\mathrm{NH}$, and several studies have demonstrated reading skill to be at level with children with NH in the ages 10-12 years. Geers et al., however, found that children with $\mathrm{Cl}$ as a group do not perform at level with their peers at ages $15-17$ years.

The sample in this study was the same as in Study I, except for two children who chose to decline the tests of reading skill. Two measures of reading skill were administered at the same time as data collection for Study I was performed. One measure, Towre, was of decoding skill and consisted of two lists of real words and two lists of non-words; the participant had 45 seconds for each list to read out loud as many words as possible. The other measure was of reading comprehension, Woodcock, and consisted of incomplete sentences, where the task was to complete the sentence with a grammatically and semantically correct word. One child chose to decline this measure of reading comprehension. Performance of the children with $\mathrm{USH} 1+\mathrm{Cl}$ was described in relation to their performance on the cognitive measures, and to that of children with $\mathrm{NH}$, children with $\mathrm{HI}+\mathrm{HA}$, and children with other types of deafness and $\mathrm{Cl}$. The findings were that there were no differences in reading comprehension, or in decoding score between groups. However, the case studies displayed that two of the youngest children with $\mathrm{USH} 1+\mathrm{Cl}$, who had high performance on the measures of cognitive measures, had decoding strategies similar to those observed in children with $\mathrm{NH}$, and reading comprehension in line with the mean value of this control group. The oldest child displayed generally low performance on the cognitive measures, poor decoding skill, and low scores on reading comprehension. The findings of this study was in line with previous research with children with $\mathrm{Cl}$ which has shown the variation in performance to be greater in this group, and that outcome with $\mathrm{Cl}$ is influenced by age at implantation. 
Paper III.

The aim of this study was to examine the same basic cognitive abilities as in Study I (phonological skill, lexical skill, and working memory), and reading, in adults with Usher syndrome type 2 (USH2). Participants were recruited through the Örebro Audiological Research Centre's database on Usher Syndrome. Thirteen adults with USH2 in the age-range 21-60 years each participated during a test session of 2.5 hours. Each participant was matched on age and level of education to a control with normal hearing and vision. The settings of color of background and text and font size in the tests, where visual stimuli were used, could be adapted by each participant in order to enhance visibility. For verbal instructions and for tests with auditory stimuli radio-transmitting FM-systems could be applied to increase audibility. The results were that the group with USH2 performed significantly poorer on complex verbal WM, on phonological skill and on phonological working memory. There was also a significant difference in performance on the test typically used as a baseline measure, where the stimuli are visual and speeded judgment is required (See Figure 4). The group with USH2 had significantly longer reaction times on the tests of phonological (See Figure 5) and lexical skill. There were no differences in performance between the groups on the lexical measure or in reading comprehension scores. The conclusions were that adults with USH2 displayed similar difficulties with phonological processing as individuals with long-term hearing loss, and also that adults with USH2 compensated for the poor vision by allowing more time on visual tasks. 


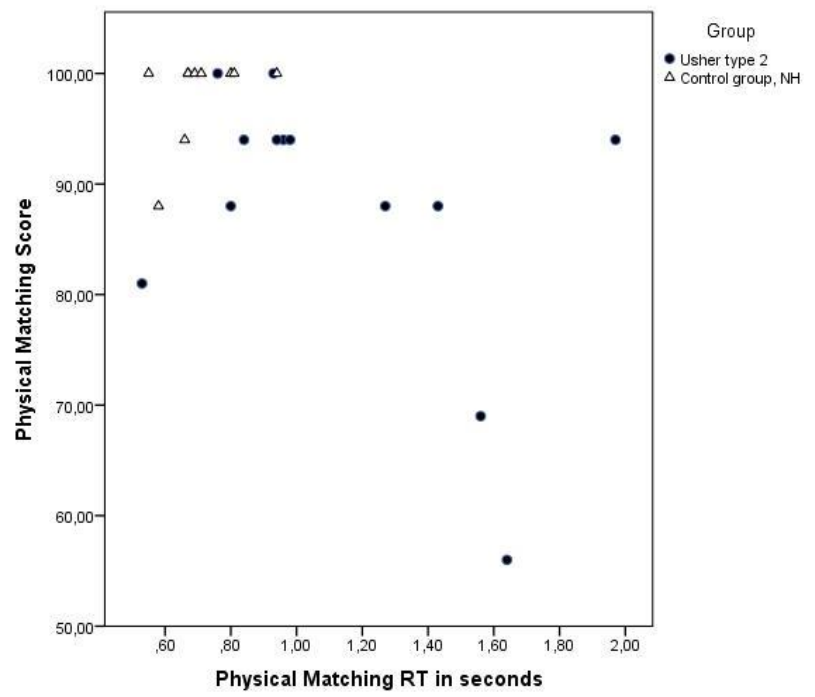

Figure 4: Scatterplot displaying the relation between score and RT on Physical Matching in both groups. Several individuals in the group with USH2 have long RTs and performance below expected.

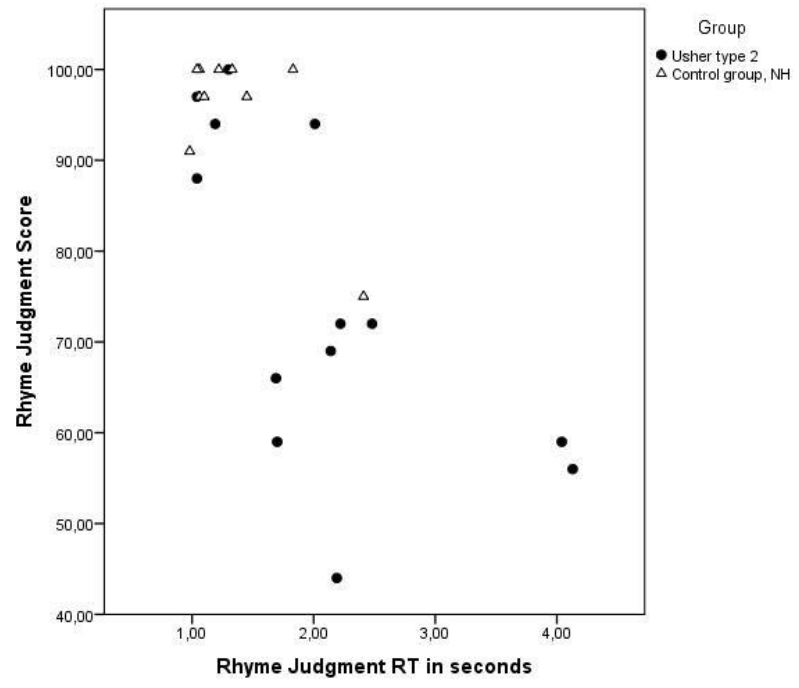

Figure 5: Scatterplot displaying the relation between RT and performance on a measure of phonological skills: Rhyme Judgment. About half of the group with USH2 displayed both long RTs and low scores on this measure. 
Paper IV.

The aim of this study was to examine theory of mind (ToM) in individuals with USH2, and to compare their performance to that of individuals with another syndrome causing deafblindness, i.e., Alström syndrome (AS), as well as to the performance of a matched control group. The group of participants with USH2 was the same as in Study III. The group of participants with AS consisted of 12 individuals, who had been recruited via their interest organizations. The control group consisted of 33 individuals with normal hearing and vision, each matched to a participant with deafblindness on age and level of education. All participants performed Happé's Strange Stories test, which consists of three parts; one measure of basic processing and recall of verbal material, the other a measure of verbal reasoning and problem solving, and the third a measure of ToM. All participants also performed a measure of complex working memory for verbal material, namely, Reading Span. Results were that there were no significant difference between groups in performance on basic processing and recall of verbal material. There was no significant difference between the control group and the group with USH2 on complex working memory for verbal material, while the group with Alström had significantly lower performance than both other groups on this test. The control group with NVH had significantly higher performance than the two groups with deafblindness on verbal reasoning and problem solving, while the groups with deafblindness did not differ significantly. The control group had significantly higher performance on ToM than the two groups with deafblindness, but there was also a significant difference between the two groups with deafblindness, in as much as the group with USH2 had significantly higher performance than the group with AS. Findings were also that the variation in performance among individuals with deafblindness was greater than among the participants in the control group. Also, a majority of participants with USH2 performed within one standard deviation of the control group's mean value on the ToM measure, compared to a minority of the participants with AS. The conclusions were that onset of visual loss might have an impact on ToM, but also that other factors than deafblindness are likely to impact the development of, or in this case, the ability to employ the ability of ToM. 


\section{General discussion}

\section{Summary of Empirical Findings}

As described by Lyxell et al. (2009), Nakeva von Mentzer (2014), and Wass (2009), performance on tests taxing phonological processing is commonly less exact and more often erroneous in children with $\mathrm{Cl}$ and $\mathrm{HI}+\mathrm{HA}$. This is particularly true in children with profound deafness and $\mathrm{Cl}$ (Geers et al., 2008; Lyxell et al., 2009; Nicholas \& Geers, 2007; Peterson et al., 2010). However, the variation in performance in the group of children with $\mathrm{Cl}$ on these tests is typically very large, though there is a clear trend of higher performance for children with early implantation (Geers \& Sedey, 2011; Lyxell et al., 2009; Peterson et al., 2010; Spencer \& Tomblin, 2009). The findings would seem to be valid also in the case of the children with $\mathrm{USH} 1+\mathrm{Cl}$. In the two studies of children with $\mathrm{USH} 1+\mathrm{Cl}$, the younger children with early insertion of $\mathrm{Cl}$, had results indicating an ability to identify and separate speech sounds at level with that of children with $\mathrm{NH}$ of the same age. However, the capacity of phonological WM, which is most important for the building of phonological representations and vocabulary, was below the levels of children with NH for all but one participant with USH $1+\mathrm{Cl}$. Possibly, this finding could be part of the explanation behind the poor, and within each individual varied, performance on the tests of lexical skill. Nevertheless, the performance of the children with $\mathrm{USH} 1+\mathrm{Cl}$ on the reading tasks did not differ from the performance of the control group with $\mathrm{NH}$, or the other control groups. This may indicate that the ability to read can develop on the basis of other cognitive skills than phonological ones; it is, for instance, possible that children with $\mathrm{Cl}$ develop an orthographic strategy, as suggested by Wass (2009). Another possibility would be that the level of phonological skill that has developed in the children with USH1+CI by the ages 7-12 years is sufficient to sustain reading at the level of difficulty and complexity expected from children in general at that age.

Adults with USH2 displayed a pattern of performance on the tests of phonological processing typical for individuals with long term duration of hearing loss (Andersson, 2001; Classon et al., 2013; Hulme et al., 2012). Most of the individuals had difficulties with tasks taxing phonological skills, and all had poor accuracy of recall on the measure of phonological working memory. However, despite these processing difficulties, performance on tests of reading skill and the general aspect of theory of mind was at the same level as in the control group with $\mathrm{NH}$. The hearing loss has been present from birth for these individuals, and possibly the majority have found ways to compensate the loss of auditory information, for example, by using technical aids, compensation strategies, such as, asking for clarifications, or requesting information to be given in several modalities. However, most of the participants with USH2 displayed unexpectedly low performance on the part of Strange Stories, which tax verbal reasoning and logic. Possibly, efficient phonological processing, which is dependent on rich auditory stimulation, is necessary in order for verbal problem solving of complex problems to function smoothly, with low rate of errors. It is also possible that those individuals, who also displayed poor performance on the ToM part of the test, 
did so as a result of poor language skills. The individuals with lowest performance on ToM in the present study also displayed generally low performance across all cognitive tasks (phonological processing, WM, and reading) in the study. It is important to note that variation in performance was relatively large, both between and within participants. All but three individuals with USH2 performed at level with the control group on at least one of the tests, and these three displayed generally high performance with exception of Rhyme judgment and phonological WM.

\section{General performance}

The main contribution from the present research is the description of previously specified cognitive skills in the groups of children with USH1 and adults with USH2. Historically, Usher syndrome was described as commonly concurrent with mental retardation (Hallgren, 1959). Similarly, Dammeyer $(2015 ; 2012)$ suggests that there is a higher prevalence of psychiatric illness in the group with USH1, as well as suggesting that cognitive issues could be more common among individuals with the diagnosis. However, the findings in the present thesis refutes that general cognitive problems would be prevalent in the group. On the contrary, the majority of individuals in the present thesis, both children and adults, came across as high performers with good general capacity. The majority of the children displayed performance above the norm on the control measure Block Design from the Wechsler Intelligence Scales for Children. There was no such control measure used with the adult group, and instead all tests were of the type specifically aimed at cognitive skills that could be impacted by the sensory impairments. However, despite the elevated level of difficulty experienced by the group with USH2 (due to the sensory impairments) almost all individuals performed close to maximum score on at least one of all the tests given during the session. Parenthetically, all participants with USH2 took part in group interviews for another project during the weekend when data collection was made. In a personal comment the individuals responsible for the interviews described how impressed they were by the participants' complex and insightful discussions.

\section{The bio-psycho-social perspective}

It is important to note that the participants with USH achieve their performance in spite of limited access to information due to the sensory losses. If one applies the bio-psycho-social perspective on the situation for individuals with USH, it can be argued that the combination of hearing and visual impairment on the biological level, impacts primarily phonological processing on the psychological level, and together these two levels interfere with the social level, creating greater difficulties, for instance, in participation in all contexts. A common strategy for individuals with hearing impairment is to attend to visual information to a higher degree, in order to compensate the loss of auditory information with visual cues (Hua et al., 2013). However, for adults with USH visual information is also deteriorated, so other compensating strategies have to be applied, and as the majority of communication takes place in the auditory and visual modalities, accessing information can become very demanding for individuals with USH2. 


\section{Cognitive skills and design of interventions}

A large proportion of individuals in both groups of participants (children and adults) struggle with phonological processing as a result of the hearing impairment, and possibly, as a consequence, they have to exert more effort in everyday situations of spoken communication than individuals with normal hearing. On top of this, the visual problems add to the cognitive load for the individuals. In the present thesis this is indicated in the adult group by long RTs on the tests with visual stimuli. The visual problems typically start to become a limiting factor for performance during the adolescent years in individuals with USH1 and 2 (Sadeghi, Kimberling, et al., 2004). It is, therefore, possible that the performance of the two older children with USH1+Cl was affected by problems with visibility.

Increased cognitive load is, however, likely to arise from several sources, such as, for instance, the demanding task of orientating oneself in a room when the visual field is severely restricted. Orientation with a limited visual field requires conscious application of strategies, literally "looking around" by turning of the head. Also, since the eyes because of the RP are poor at adjusting for differences in light conditions, the conditions might need to be adjusted in order for the person to see the surroundings at all. In sum, a person with USH experiences increased cognitive demands when continuously "filling in the blanks" in the auditory information, as well as when attending carefully to the limited visual input. Considering this, the findings by Wahlqvist et al. (2013) of poorer psycho-social health in respondents with USH2, in comparison to a reference population of the Swedish health survey, does not seem surprising. The respondents with USH2 in the study by Wahlqvist et al. (2013) reported higher levels of stress, fatigue, headache, pain in the shoulders and neck, and depression.

With increased knowledge about the populations with USH, there is a possibility to improve the situation, and the responsibility for compensation could, to a higher degree, rely on the people around the person with USH. When interpreting the findings in the present thesis, it seems likely that applying interventions designed for individuals with long-term hearing loss in combination with those created to relieve problems with low vision, may help this group, too. Judging by the large variation among the participants, interventions would be more beneficial if the individual levels of cognitive skill are taken into account. Whereas one person might be greatly helped by information on communication strategies directed to the person, as well as to the people in her/his different contexts, another individual might benefit more from training of specific cognitive skills (e.g., phonological skills), or cognitive strategies (e.g., memory strategies). Training of specific cognitive skills might be specifically effective with children with $\mathrm{USH} 1+\mathrm{Cl}$ in order to prevent psycho-social health issues.

Drawing on the present data, it could be especially important to ensure that individuals with USH develop sufficient phonological processing abilities and good reading skills, and to help them apply these skills as effortlessly as possible. The design of intervention could be based on a child's performance on a test battery similar to the one used in the present thesis. Such 
a battery, in combination with tests of linguistic skills (e.g., pragmatic), could give information on the individual's weaknesses and strengths and facilitate a specified and efficient intervention. The studies by, for example, Nakeva von Mentzer (2014) clearly indicate that such designed training of specific skills can be beneficial for development of composite skills such as reading. Another possible gain from specific training of phonological skills may be improved skills in hearing with the $\mathrm{Cl}$, which could be a benefit as vision declines.

Support for this latter proposition can be found in the results of the present thesis, in that phonological processing skills are important for reading skill for individuals with USH1 and 2, in a similar way as for individuals with $\mathrm{NH}$. When examining the performance of the individuals with USH, those who display most difficulties with the tasks taxing phonological processing and phonological WM also perform poorly on tests of reading comprehension. Those children with USH1+Cl who displayed difficulties in phonological processing also performed poorly on decoding of words and non-words. In the adults, difficulties in phonological processing and phonological WM concurred with low results on verbal reasoning and verbal problem solving on the Physical stories and with inability to give nuanced and full answers to the verbally presented problems with social content (ToM). Hence, it would seem that interception of individuals who are at risk of developing problems with phonological skills would be beneficial. If individuals are able to appreciate reading, they then have access to a source of information, which can make them more proficient in language (Hermans et al., 2008; Verhoeven \& Perfetti, 2011) and also help them develop better understanding of other people's perspectives and motives (Mar et al., 2006; Kidd \& Castano, 2013).

\section{Theory of mind in individuals with deafblindness}

Regarding ToM in the adults, it would appear that it is not deafblindness per se that impacts the ability but rather to what extent the sensory impairments have been an obstacle in accessing all information in the social environment (e.g., in auditory and visual modes of relating and communicating). In the fourth study, the group with USH2 performed at the same level as the control group with NVH in terms of raw score on the test, whereas individuals with Alström Syndrome performed significantly poorer on ToM, both in terms of raw scores and in terms of quality and nuances of the answers (number of correct mental references). Individuals with USH2 have late onset of RP, thus imposing little restriction in amount of visual information acquired during childhood and adolescence. Also, since the $\mathrm{HI}$ is congenital and relatively stable over the lifespan, most individuals with USH 1 and 2 receive rehabilitation at an early age, aimed at helping to compensate the potential loss of information. Thus, the case might be that lower language proficiency, via poorer phonological processing, impacts quality of the answers to the ToM questions in the few individuals with USH2 who performed below the control group.

In contrast, the majority in the group with AS had early onset of blindness, and there was a clear relationship between later onset and higher score (Frölander et al., 2014). All 
individuals with AS have a congenital, mild $\mathrm{HL}$, which progresses to a moderate-to-severe $\mathrm{HL}$ in the ages 25-30 years (Rönnåsen et al., in press). Hence, their ability to acquire visual and auditory information is severely limited from an early age. This will most likely impact the amount and quality of social experience that they receive, impeding development of ToM. Another factor, which cannot be ruled out, is that poor ToM also could be caused by the ALMS gene, which seems to be active in most organs of the body.

\section{Discussion on methods}

There are several challenges in performing research on small and unique populations like individuals with USH. These challenges consist both of protecting the participants from being over-exposed and of achieving a large enough amount of data, as the number of individuals with the condition is low. Another challenge lies in finding ways to use the data in as informational ways as possible. There was also the issue of lack of previous research with a cognitive perspective on the population, and, hence, the research questions had to be descriptive in nature. The present thesis relies on tests that yield quantitative data, and by using slightly untraditional statistical methods we can present some new knowledge regarding how individuals with USH perform on the specified cognitive skills in relation to other populations. A quantitative approach was at this stage most suitable in order to describe the group and to generate knowledge. There are very few psycho-social studies in deafblindness, the reasons behind this being that the syndromes are heterogeneous and rare. The studies in the present thesis, despite the somewhat small number of participants, have had access to one of the largest cohorts in the world of Usher syndrome type 2 with longitudinal data on vision and hearing via the database on USH. However, useful information could have been collected by using charts for observations during the test sessions, or by giving out questionnaires on, for example, reading habits. Adding qualitative data to the descriptions of the groups with USH, based on the quantitative data, might have given more nuanced information on performance of the individuals, without risking the integrity of the participants. Specifically, as there are so few potential participants, studies such as the ones included in the present thesis also have to be careful to include too many tests or test sessions, as taking cognitive tests is often demanding. Hence, repeated sessions with large batteries of cognitive tests would be exhausting, possibly decreasing motivation to participate in research studies. Future studies using qualitative methods might give new and valuable insights.

\section{Conslusions}

To conclude, the groups of adults and children with USH display poor levels of phonological skills and phonological WM, due to the congenital hearing impairment, and they display a similar performance level as other populations with hearing impairment. The poorer phonological processing does, however, not seem to impact the composite cognitive skills of reading (cf., Nakeva von Mentzer, 2014; Wass, 2009) or ToM to any noticeable degree in the majority of individuals with USH1 and 2. Nevertheless, it is possible that poor phonological processing may impact on the amount of effort that needs to be exerted in everyday 
communication, and in combination with the progressive visual impairment the strain on the individual increases. The children with USH1+Cl may as adults experience a comparable combination of difficulties with phonological processing and visual limitations as that of the adults with USH 2 in the present study. Hence, interventions aimed at improving phonological processing skill as early as possible may be preventive.

\section{Future Directions}

Future studies on populations with USH will have to face the inherent challenges of research on small populations, and will also have to deal with the challenges in appropriate ways. The present thesis focused on the cognitive skills that are central in auditory processing of stimuli, and more research with a focus on the cognitive skills essential for visual information-processing is needed. The tests used in the studies of the present thesis were not aimed at discerning the impact of visual impairment on cognitive skills, and, hence, more thorough investigations, for instance, by incorporating more spatial tasks, would be useful.

The acquired knowledge on the performance on phonological processing, lexical skills, WM, reading and ToM in the two groups with USH can be helpful in the generation of new studies. Future studies could formulate more precise research questions, aimed at disambiguating the impact of deafblindness on cognitive performance. This would in turn give additional information on how, for example, support and training should be designed in order to improve rehabilitation for individuals with USH. A suggestion here would be to make use of qualitative methods, in order to better understand the quantitative data but also to ensure that the perspective of individuals with USH is included in research.

Since USH is a rare condition, study samples will always be small, particularly when studies are limited to a single nation like Sweden. A way to reach more individuals with USH and increase study samples could be through international cooperation of research teams, such as could be organized through the European Union. Future projects could also benefit enormously by applying a combination of several research methods for collection of different types of data. As it is impossible to use cognitive tests for every aspect of cognition that would be of interest, it would be highly valuable to use questionnaires on, for example, reading habits or self-ratings on communication experiences. This information could be used in more in-depth case studies, which would be highly informative about the situation and experience of persons with USH. Every bit of knowledge about USH makes a difference and helps to build better understanding and, eventually, better support to individuals with the condition. Future studies on different bio-psycho-social aspects of deafblindness will hopefully make use of the findings in this thesis. 


\section{Acknowledgments}

Sedan lång tid tillbaka har jag funderat på vad jag ska skriva här. Nu är stunden kommen, och alla de formuleringar jag haft i tankarna är plötsligen svårfångade. Det finns så mycket att tacka för, och så många känslor som jag vill sätta ord på som avslutning på mitt doktorandarbete. Doktorandprojektet gjordes möjligt tack vare mina handledare Björn Lyxell, Claes Möller och Björn Lidestam, och har varit utmanande och lärorikt.

TACK till alla som deltagit i studierna, för er tid och energi under långdragna testsessioner. Ni gjorde forskningen möjlig! Jag uppskattar mycket att ha träffat er och är tacksam för allt ni lärt mig!

TACK till alla vänner och kollegor i Linköping och Örebro som stöttat, hjälpt och peppat mig igenom mitt forskningsarbete. Ni betyder så mycket för mig, och ni har gjort doktorandtiden gladare och lättsammare!

TACK till alla vänner utanför arbetet för att ni tålmodigt lyssnat till mina tirader, för goda råd och starkt stöd, för alla glada stunder och för att ni finns! Det finns inga ord för hur viktiga ni är.

TACK till mina syskon med respektive, till mina föräldrar, och till min sambos familj för att ni låtit mig avhandla min blivande avhandling vid otaliga familjeträffar, och för att ni sedan hjälpt mig att komma ihåg att livet består av mer än akademiska funderingar.

TACK till min älskade sambo Mattias Sandström som bättre än någon annan vet vad den här resan inneburit för mig, och som tålmodigt väntat, stöttat och hjälpt mig hela vägen.

Äntligen går vi mot något nytt! 


\section{References}

Aguiar, L. \& Brady, S. (1991). Vocabulary Aquisition and Reading Ability. Reading and Writing: An Interdisciplinary Journal, 3, 413-425.

Alloway, T. P., Gathercole, S. E., Willis, C., \& Adams, A.-M. (2004). A structural analysis of working memory and related cognitive skills in young children. Journal of Experimental Child Psychology, 87(2), 85-106. doi:10.1016/j.jecp.2003.10.002

Alt, M., \& Suddarth, R. (2012). Learning novel words: Detail and vulnerability of initial representations for children with specific language impairment and typically developing peers. Journal of Communication Disorders, 45(2), 84-97. doi:10.1016/j.jcomdis.2011.12.003

Andersson, U. (2001). Cognitive deafness: The deterioration of phonological representations in adults with an acquired severe hearing loss and its implications for speech understanding. Linköping University: Linköping University Electronic Press.

Apperly, I. A, Samson, D., \& Humphreys, G. W. (2009). Studies of adults can inform accounts of theory of mind development. Developmental Psychology, 45(1), 190-201. doi:10.1037/a0014098

Archibald, L. M. D., \& Gathercole, S. E. (2006). Nonword repetition: a comparison of tests. Journal of Speech, Language, and Hearing Research : JSLHR, 49(5), 970-83. doi:10.1044/1092-4388(2006/070)

Arlinger, S., Lunner, T., Lyxell, B., \& Kathleen Pichora-Fuller, M. (2009). The emergence of cognitive hearing science. Scandinavian Journal of Psychology, 50, 371-384. doi:10.1111/j.1467-9450.2009.00753.x

Ask Larsen, F., \& Damen, S. (2014). Definitions of deafblindness and congenital deafblindness. Research in Developmental Disabilities, 35(10), 2568-76. doi:10.1016/j.ridd.2014.05.029

Asker-Arnason, L., Ibertsson, T., Wass, M., Wengelin, Å., \& Sahlén, B. (2010). Picture-Elicited Written Narratives, Process and Product, in 18 Children With Cochlear Implants. Communication Disorders Quarterly, 31(4), 195-212. doi:10.1177/1525740109337734

Baddeley, A. (2003). Working memory and language: an overview. Journal of Communication Disorders, 36(3), 189-208. doi:10.1016/S0021-9924(03)00019-4

Baddeley, A. (2012). Working memory: theories, models, and controversies. Annual Review of Psychology, 63, 1-29. doi:10.1146/annurev-psych-120710-100422 
Baron-Cohen, S., Jolliffe, T., Mortimore, C., \& Robertson, M. (1997). Another advanced test of theory of mind: evidence from very high functioning adults with autism or asperger syndrome. Journal of Child Psychology and Psychiatry, and Allied Disciplines, 38(7), 813-22. Retrieved from http://www.ncbi.nlm.nih.gov/pubmed/9363580

Bennett, M. R., \& Hacker, P. M. S. (2006). Language and cortical function: conceptual developments. Progress in Neurobiology, 80(1), 20-52. doi:10.1016/j.pneurobio.2006.07.002

Berk, L. E. (2009). Child Development. Boston Mass./London: Pearson International/Allyn and Bacon.

Blaiklock, K. E. (2004). The importance of letter knowledge in the relationship between phonological awareness and reading. Journal of Research in Reading, 27(1), 36-57. doi:doi:10.1111/j.1467-9817.2004.00213.x

Boëda, B., El-Amraoui, A., Bahloul, A., Goodyear, R., Daviet, L., Blanchard, S., ... Petit, C. (2002). Myosin VIla, harmonin and cadherin 23, three Usher I gene products that cooperate to shape the sensory hair cell bundle. The EMBO Journal, 21(24), 6689-99. Retrieved from http://www.pubmedcentral.nih.gov/articlerender.fcgi?artid=139109\&tool=pmcentrez \&rendertype=abstract

Boets, B., Wouters, J., van Wieringen, A., De Smedt, B., \& Ghesquière, P. (2008). Modelling relations between sensory processing, speech perception, orthographic and phonological ability, and literacy achievement. Brain and Language, 106(1), 29-40. doi:10.1016/j.bandl.2007.12.004

Bonino, D., Ricciardi, E., Sani, L., Gentili, C., Vanello, N., Guazzelli, M., ... Pietrini, P. (2008). Tactile spatial working memory activates the dorsal extrastriate cortical pathway in congenitally blind individuals. Archives Italiennes de Biologie, 146(3-4), 133-146. Retrieved from http://europepmc.org/abstract/MED/19378878

Briscoe, J., Bishop, D. V, \& Norbury, C. F. (2001). Phonological processing, language, and literacy: a comparison of children with mild-to-moderate sensorineural hearing loss and those with specific language impairment. Journal of Child Psychology and Psychiatry, and Allied Disciplines, 42(3), 329-40. Retrieved from http://www.ncbi.nlm.nih.gov/pubmed/11321202

Carpenter, M., Nagell, K., \& Tomasello, M. (1998). Social Cognition, Joint Attention, and Communcative Competence from 9 to 15 Months of Age, (with Commentary by G. 
Butterworth and C. Moore). Monographs of the society for research in child development, 63(4).

Caselli, M. C., Bates, E., Casadio, P., Fenson, J., Fenson, L., Sanderl, L., \& Weir, J. (1995). A cross-linguistic study of early lexical development. Cognitive Development, 10, 159199. doi:10.1016/0885-2014(95)90008-X

Chan, R. C. K., Shum, D., Toulopoulou, T., \& Chen, E. Y. H. (2008). Assessment of executive functions: review of instruments and identification of critical issues. Archives of Clinical Neuropsychology: The Official Journal of the National Academy of Neuropsychologists, 23(2), 201-16. doi:10.1016/j.acn.2007.08.010

Classon, E., Rudner, M., \& Rönnberg, J. (2013). Working memory compensates for hearing related phonological processing deficit. Journal of Communication Disorders, 46(1), 1729. doi:10.1016/j.jcomdis.2012.10.001

Conway, A. R. A., Jarrold, C., Kane, M. J., Miyake, A., \& Towse, J. N. (2007). Variation in Working Memory. Oxford University Press, USA. Retrieved from http://www.google.se/books?id=qubgq-cnbOkC

Cremers, F. P. M., Kimberling, W. J., Külm, M., de Brouwer, A. P., van Wijk, E., te Brinke, H., ... Kremer, H. (2007). Development of a genotyping microarray for Usher syndrome. Journal of Medical Genetics, 44(2), 153-60. doi:10.1136/jmg.2006.044784

Cutting, L. E., \& Scarborough, H. S. (2006). Prediction of Reading Comprehension: Relative Contributions of Word Recognition, Language Proficiency, and Other Cognitive Skills Can Depend on How Comprehension Is Measured. Scientific Studies of Reading, 10(3), 277-299. doi:10.1207/s1532799xssr1003

Dammeyer, J. (2010). Prevalence and aetiology of congenitally deafblind people in Denmark. International Journal of Audiology, 49(2), 76-82. doi:10.3109/14992020903311388

Dammeyer, J. (2012). Children with Usher syndrome: mental and behavioral disorders. Behavioral and Brain Functions : BBF, 8(1), 16. doi:10.1186/1744-9081-8-16

Dammeyer, J. H. (2015). Living with dual sensory loss. Prevalence, aetiology, and mental and behavioural disorders among people with deafblindness and associated syndromes: Rubella, Usher, and CHARGE syndrome. PhD-thesis: University of Copenhagen.

http://www.psy.ku.dk/Kalender/jesper dammeyer doktorforsvar/resume/

De Jaegher, H., Di Paolo, E., \& Gallagher, S. (2010). Can social interaction constitute social cognition? Trends in Cognitive Sciences, 14(10), 441-447.

doi:10.1016/j.tics.2010.06.009 
Dillon, C. M., de Jong, K., \& Pisoni, D. B. (2012). Phonological awareness, reading skills, and vocabulary knowledge in children who use cochlear implants. Journal of Deaf Studies and Deaf Education, 17(2), 205-26. doi:10.1093/deafed/enr043

Dodd, B., \& Conn, L. (2000). The effect of Braille orthography on blind children's phonological awareness. Journal of Research in Reading, 23(1), 1-11. doi:10.1111/1467-9817.00098

Dorman, M. F., Sharma, A., Gilley, P., Martin, K., \& Roland, P. (2007). Central auditory development: evidence from CAEP measurements in children fit with cochlear implants. Journal of Communication Disorders, 40(4), 284-94.

doi:10.1016/j.jcomdis.2007.03.007

Doucet, M. E., Bergeron, F., Lassonde, M., Ferron, P., \& Lepore, F. (2006). Cross-modal reorganization and speech perception in cochlear implant users. Brain : A Journal of Neurology, 129(Pt 12), 3376-83. doi:10.1093/brain/awl264

Engel de Abreu, P. M. J., Gathercole, S. E., \& Martin, R. (2011). Disentangling the relationship between working memory and language: The roles of short-term storage and cognitive control. Learning and Individual Differences, 21(5), 569-574.

doi:10.1016/j.lindif.2011.06.002

Eysenck, M. W., \& Keane, M. T. (2003). Cognitive Psychology. A Student's Handbook (4th ed.). New York: Psychology Press.

Frölander, H. E., Möller, C., Marshall, J. D., Sundqvist, A., Rönnåsen, B., Falkensson, L., \& Lyxell, B. (2014). Theory-of-mind in adolescents and young adults with Alström syndrome. International Journal of Pediatric Otorhinolaryngology, 78(3), 530-6. doi:10.1016/j.ijporl.2013.12.038

Furnes, B., \& Samuelsson, S. (2011). Phonological awareness and rapid automatized naming predicting early development in reading and spelling: Results from a cross-linguistic longitudinal study. Learning and Individual Differences, 21(1), 85-95. doi:10.1016/j.lindif.2010.10.005

Gaab, N., \& Schlaug, G. (2003). Musicians differ from nonmusicians in brain activiation despite performance matching. Annals of the New York Academy of Sciences, (999), 385-388. doi:10.1196/annals.1284.048

Garfield, J. L., Peterson, C. C., \& Perry, T. (2001). Social cognition, language acquisition and the development of the theory of mind. Mind \& Language, 16(5), 494-541. doi:10.1111/1468-0017.00180 
Gaskell, M. G., \& Marslen-Wilson, W. D. (2002). Representation and competition in the perception of spoken words. Cognitive Psychology, 45(2), 220-266. doi:10.1016/S00100285(02)00003-8

Gathercole, S. E. (2006). Nonword repetition and word learning: The nature of the relationship. Applied Psycholinguistics, 27(04), 513-543. doi:10.1017/S0142716406060383

Gathercole, S. E., Alloway, T. P., Willis, C., \& Adams, A.-M. (2006). Working memory in children with reading disabilities. Journal of Experimental Child Psychology, 93(3), 26581. doi:10.1016/j.jecp.2005.08.003

Geers, A. E., \& Sedey, A. L. (2011). Language and verbal reasoning skills in adolescents with 10 or more years of cochlear implant experience. Ear and Hearing, 32(1 Suppl), 39S48S. doi:10.1097/AUD.0b013e3181fa41dc

Geers, A., Tobey, E., Moog, J., \& Brenner, C. (2008). Long-term outcomes of cochlear implantation in the preschool years: from elementary grades to high school. International Journal of Audiology, 47 Suppl 2, S21-30. doi:10.1080/14992020802339167

Giacomello, M., De Mario, A., Lopreiato, R., Primerano, S., Campeol, M., Brini, M., \& Carafoli, E. (2011). Mutations in PMCA2 and hereditary deafness: a molecular analysis of the pump defect. Cell Calcium, 50(6), 569-76. doi:10.1016/j.ceca.2011.09.004

Giraud, A.-L., \& Lee, H.-J. (2007). Predicting cochlear implant outcome from brain organisation in the deaf. Restorative Neurology and Neuroscience, 25(3-4), 381-90. Retrieved from http://www.ncbi.nlm.nih.gov/pubmed/17943013

Goldrick, M., \& Rapp, B. (2007). Lexical and post-lexical phonological representations in spoken production. Cognition, 102, 219-260. doi:10.1016/j.cognition.2005.12.010

Gonsoulin, T. P. (2001). Cochlear implant/Deaf World dispute: Different bottom elephants. Otolaryngology - Head and Neck Surgery, 125, 552-556. doi:10.1067/mhn.2001.119320

Greaney, J., \& Reason, R. (1999). Phonological processing in Braille. Dyslexia, 5(4), 215-226. doi:10.1002/(SICI)1099-0909(199912)5:4<215::AID-DYS145>3.0.CO;2-G

Hallgren, B. (1959). Retinitis Pigmentosa combined with Congenital Deafness with VestibuloCerebellar Ataxia and Mental Abnormalities in a proportion of cases. A Clinical Genetico-statistical study. Acta Psychiatrica Scandinavia, 34(138), 5-101. 
Happé, F. G. (1994). An advanced test of theory of mind: understanding of story characters' thoughts and feelings by able autistic, mentally handicapped, and normal children and adults. Journal of Autism and Developmental Disorders, 24(2), 129-54. Retrieved from http://www.ncbi.nlm.nih.gov/pubmed/8040158

Hayes, H., Geers, A. E., Treiman, R., \& Moog, J. S. (2009). Receptive vocabulary development in deaf children with cochlear implants: achievement in an intensive auditory-oral educational setting. Ear and Hearing, 30(1), 128-35. doi:10.1097/AUD.0b013e3181926524

Hensch, T. K. (2005). Critical period plasticity in local cortical circuits. Nature Reviews. Neuroscience, 6(11), 877-88. doi:10.1038/nrn1787

Hermans, D., Knoors, H., Ormel, E., \& Verhoeven, L. (2008). The relationship between the reading and signing skills of deaf children in bilingual education programs. Journal of Deaf Studies and Deaf Education, 13(4), 518-30. doi:10.1093/deafed/enn009

Høien, T., Lundberg, I., Stanovich, K. E., \& Bjaalid, I.-K. (1995). Components of phonological awareness. Reading and Writing, $7(2), 171-188$.

Hua, H., Karlsson, J., Widén, S., Möller, C., \& Lyxell, B. (2013). Quality of life, effort and disturbance perceived in noise: a comparison between employees with aided hearing impairment and normal hearing. International Journal of Audiology, 52(9), 642-9. doi:10.3109/14992027.2013.803611

Hulme, C., Bowyer-Crane, C., Carroll, J. M., Duff, F. J., \& Snowling, M. J. (2012). The causal role of phoneme awareness and letter-sound knowledge in learning to read: combining intervention studies with mediation analyses. Psychological Science, 23(6), 572-7. doi:10.1177/0956797611435921

Hötting, K., \& Röder, B. (2009). Auditory and auditory-tactile processing in congenitally blind humans. Hearing Research, 258(1-2), 165-74. doi:10.1016/j.heares.2009.07.012

Iversen, E. H. (2011). Assigning Voices : Interactions among Human, Parental and Cultural Rights over Deaf Children. Honors Theses, paper 603, Middeltown, Con.:Wesleyan University.

Jacquemot, C., Dupoux, E., Decouche, O., \& Bachoud-Levi, A.-C. (2006). Misperception in sentences but not in words: Speech perception and the phonological buffer. Cognitive Neuropsychology, 23(6), 949-71. doi:10.1080/02643290600625749 
Jacquemot, C., \& Scott, S. K. (2006). What is the relationship between phonological shortterm memory and speech processing? Trends in Cognitive Sciences, 10(11), 480-6. doi:10.1016/j.tics.2006.09.002

Jolliffe, T., \& Baron-Cohen, S. (1999). The Strange Stories Test: a replication with highfunctioning adults with autism or Asperger syndrome. Journal of Autism and Developmental Disorders, 29(5), 395-406. Retrieved from http://www.ncbi.nlm.nih.gov/pubmed/10587886

Joy, T., Cao, H., Black, G., Malik, R., Charlton-Menys, V., Hegele, R. A, \& Durrington, P. N. (2007). Alstrom syndrome (OMIM 203800): a case report and literature review. Orphanet Journal of Rare Diseases, 2(Omim 203800), 49. doi:10.1186/1750-1172-2-49

Kidd, D. C., \& Castano, E. (2013). Reading literary fiction improves theory of mind. Science (New York, N.Y.), 342(October), 377-80. doi:10.1126/science.1239918

Kral, A., \& Eggermont, J. J. (2007). What's to lose and what's to learn: development under auditory deprivation, cochlear implants and limits of cortical plasticity. Brain Research Reviews, 56(1), 259-69. doi:10.1016/j.brainresrev.2007.07.021

Kral, A., \& Sharma, A. (2012). Developmental neuroplasticity after cochlear implantation. Trends in Neurosciences, 35(2), 111-22. doi:10.1016/j.tins.2011.09.004

Kremer, H., van Wijk, E., Märker, T., Wolfrum, U., \& Roepman, R. (2006). Usher syndrome: molecular links of pathogenesis, proteins and pathways. Human Molecular Genetics, 15 Spec No(2), R262-70. doi:10.1093/hmg/ddl205

Lazard, D. S., Giraud, A-L., Gnansia, D., Meyer, B., \& Sterkers, O. (2012). Understanding the deafened brain: implications for cochlear implant rehabilitation. European Annals of Otorhinolaryngology, Head and Neck Diseases, 129(2), 98-103. doi:10.1016/j.anorl.2011.06.001

Lederberg, A. R., Schick, B., \& Spencer, P. E. (2013). Language and literacy development of deaf and hard-of-hearing children: successes and challenges. Developmental Psychology, 49(1), 15-30. doi:10.1037/a0029558

Lee, H.-J., Truy, E., Mamou, G., Sappey-Marinier, D., \& Giraud, A.-L. (2007). Visual speech circuits in profound acquired deafness: a possible role for latent multimodal connectivity. Brain : A Journal of Neurology, 130(Pt 11), 2929-41. doi:10.1093/brain/awm230

Lewis, C., Freeman, N. H., Kyriakidou, C., Maridaki-Kassotaki, K., \& Berridge, D. M. (1996). Social influences on false belief access: specific sibling influences or general 
apprenticeship? Child Development, 67, 2930-2947. doi:10.1111/j.1467-

8624.1996.tb01896.x

Lomber, S. G., Meredith, M. A., \& Kral, A. (2010). Cross-modal plasticity in specific auditory cortices underlies visual compensations in the deaf. Nature Neuroscience, 13(11), 1421-7. doi:10.1038/nn.2653

Low, J., \& Perner, J. (2012). Implicit and explicit theory of mind: state of the art. The British Journal of Developmental Psychology, 30(Pt 1), 1-13. doi:10.1111/j.2044835X.2011.02074.x

Lundberg, I. (2009). Early precursors and enabling skills of reading acquisition. Scandinavian Journal of Psychology, 50(6), 611-616. doi:10.1111/j.1467-9450.2009.00778.x

Lyxell, B., Andersson, J., Andersson, U., Arlinger, S., Bredberg, G., \& Harder, H. (1998). Phonological representation and speech understanding with cochlear implants in deafened adults. Scandinavian Journal of Psychology, 39(3), 175-9. Retrieved from http://www.ncbi.nlm.nih.gov/pubmed/9800533

Lyxell, B., Andersson, J., Arlinger, S., Bredberg, G., Harder, H., \& Rönnberg, J. (1996). Verbal information-processing capabilities and cochlear implants: implications for preoperative predictors of speech understanding. Journal of Deaf Studies and Deaf Education, 1(3), 190-201. Retrieved from http://www.ncbi.nlm.nih.gov/pubmed/15579823

Lyxell, B., Wass, M., Sahlén, B., Ibertsson, T., Asker-Arnason, L., \& Uhlén, I. (2013). Hearing and Cognitive Development in Deaf and Hearing-impaired Children: Effects of Intervention. In G. G. Celesia (Ed.), Handbook of clinical neurophysiology (pp. 71-80). Elsevier B.V.

Lyxell, B., Wass, M., Sahlén, B., Samuelsson, C., Asker-Arnason, L., Ibertsson, T., ... Hällgren, M. (2009). Cognitive development, reading and prosodic skills in children with cochlear implants. Scandinavian Journal of Psychology, 50(5), 463-74. doi:10.1111/j.14679450.2009.00754.x

Löfkvist, U., Almkvist, O., Lyxell, B., \& Tallberg, I.-M. (2014). Lexical and semantic ability in groups of children with cochlear implants, language impairment and autism spectrum disorder. International Journal of Pediatric Otorhinolaryngology, 78(2), 253-63. doi:10.1016/j.ijporl.2013.11.017

Maehara, Y., \& Saito, S. (2007). The relationship between processing and storage in working memory span: Not two sides of the same coin. Journal of Memory and Language, 56(2), 212-228. doi:10.1016/j.jml.2006.07.009 
Mampe, B., Friederici, A. D., Christophe, A., \& Wermke, K. (2009). Newborns' cry melody is shaped by their native language. Current Biology : CB, 19(23), 1994-7. doi:10.1016/j.cub.2009.09.064

Mar, R. A., Oatley, K., Hirsh, J., dela Paz, J., \& Peterson, J. B. (2006). Bookworms versus nerds: Exposure to fiction versus non-fiction, divergent associations with social ability, and the simulation of fictional social worlds. Journal of Research in Personality, 40, 694-712. doi:10.1016/j.jrp.2005.08.002

Marchman, V. A, \& Fernald, A. (2008). Speed of word recognition and vocabulary knowledge in infancy predict cognitive and language outcomes in later childhood. Developmental Science, 11(3), F9-16. doi:10.1111/j.1467-7687.2008.00671.x

Marshall, J. D., Beck, S., Maffei, P., \& Naggert, J. K. (2007). Alström syndrome. European Journal of Human Genetics : EJHG, 15(12), 1193-202. doi:10.1038/sj.ejhg.5201933

Mauldin, L. (2013). Precarious Plasticity: Neuropolitics, Cochlear Implants, and the Redefinition of Deafness. Science, Technology \& Human Values, 39(1), 130-153. doi:10.1177/0162243913512538

McGeown, S. P., Johnston, R. S., \& Medford, E. (2012). Reading instruction affects the cognitive skills supporting early reading development. Learning and Individual Differences, 22(3), 360-364. doi:10.1016/j.lindif.2012.01.012

Minter, M., Hobson, R. P., \& Bishop, M. (1998). Congenital visual impairment and "theory of mind," British Journal of Developmental Psychology, 16 (2), 183-196. doi:10.1111/j.2044-835X.1998.tb00918.x

Moore, B. C. J., Tyler, L. K., \& Marslen-Wilson, W. (2008). Introduction. The perception of speech: from sound to meaning. Philosophical Transactions of the Royal Society of London. Series B, Biological Sciences, 363(1493), 917-921. doi:10.1098/rstb.2007.2195

Müller, U., Liebermann-Finestone, D. P., Carpendale, J. I. M., Hammond, S. I., \& Bibok, M. B. (2012). Knowing minds, controlling actions: The developmental relations between theory of mind and executive function from 2 to 4 years of age. Journal of Experimental Child Psychology, 111, 331-348. doi:10.1016/j.jecp.2011.08.014

Möller, C. (2007). Deafblindness. In A. Martini, D. Stephens, \& A. P. Read (Eds.) Genes, Hearing, and Deafness: From Molecular Biology to Clinical Practice. (1st ed.). London: Informa Healthcare. Retrieved from http://www.google.se/books?id=X6jJ7004NPsC 
Möller, K. (2003). Deafblindness: a challenge for assessment--is the ICF a useful tool? International Journal of Audiology, 42 Suppl 1, S140-S142. doi:10.3109/14992020309074635

Nakeva Von Mentzer, C. (2014). Rethinking Sound: Computer-assisted reading intervention with a phonics approach for deaf and hard of hearing children using cochlear implants or hearing aids. Thesis in disability research: Linköping University. Retrieved from: 10.3384/diss.diva-108902

Nakeva von Mentzer, C., Lyxell, B., Sahlén, B., Wass, M., Lindgren, M., Ors, M., ... Uhlén, I. (2013). Computer-assisted training of phoneme-grapheme correspondence for children who are deaf and hard of hearing: Effects on phonological processing skills. International Journal of Pediatric Otorhinolaryngology, 77(12), 2049-57. doi:10.1016/j.ijporl.2013.10.007

Ng, E. H. N., Rudner, M., Lunner, T., Pedersen, M. S., \& Rönnberg, J. (2013). Effects of noise and working memory capacity on memory processing of speech for hearing-aid users. International Journal of Audiology, 52(7), 433-41. doi:10.3109/14992027.2013.776181

NIDCD. (2011). Fact sheet: Cochlear Implants, NIH Publication No. 11-4798. 1-4. URL: https://www.nidcd.nih.gov/health/hearing/pages/coch.aspx

Nicholas, J. G., \& Geers, A. E. (2007). Will they catch up? The role of age at cochlear implantation in the spoken language development of children with severe to profound hearing loss. Journal of Speech, Language, and Hearing Research : JSLHR, 50(4), 104862. doi:10.1044/1092-4388(2007/073)

Pantev, C., Ross, B., Fujioka, T., Trainor, L. J., Schulte, M., \& Schulz, M. (2003). Music and Learning-Induced Cortical Plasticity. Annals of the New York Academy of Sciences, 999, 438-450. doi:10.1196/annals.1284.054

Pennings, R. (2004). Hereditary Deaf-Blindness clinical and genetic aspects. Raboud University of Nijmegen. Retrieved from http://hdl.handle.net/2066/58910

Peterson, N. R., Pisoni, D. B., \& Miyamoto, R. T. (2010). Cochlear implants and spoken language processing abilities: review and assessment of the literature. Restorative Neurology and Neuroscience, 28(2), 237-50. doi:10.3233/RNN-2010-0535

Pring, L. (1994). Touch and go: Learning to read Braille, Reading Research Quarterly, 29(1), 66-74. Retrieved from http://eprints.gold.ac.uk/5739/ 
Rokem, A., \& Ahissar, M. (2009). Interactions of cognitive and auditory abilities in congenitally blind individuals. Neuropsychologia, 47(3), 843-8. doi:10.1016/j.neuropsychologia.2008.12.017

Rowe, M. L., \& Goldin-Meadow, S. (2009). Early gesture selectively predicts later language learning. Developmental Science, 12(1), 182-7. doi:10.1111/j.1467-7687.2008.00764.x

Ruben, R. J., \& Schwartz, R. (1999). Necessity versus sufficiency: the role of input in language acquisition. International Journal of Pediatric Otorhinolaryngology, 47(2), 137-40. Retrieved from http://www.ncbi.nlm.nih.gov/pubmed/10206361

Rudner, M., Rönnberg, J., \& Lunner, T. (2011). Working memory supports listening in noise for persons with hearing impairment. Journal of the American Academy of Audiology, 22(3), 156-67. doi:10.3766/jaaa.22.3.4

Rönnberg, J., Lunner, T., Zekveld, A., Sörqvist, P., Danielsson, H., Lyxell, B., ... Rudner, M. (2013). The Ease of Language Understanding (ELU) model: theoretical, empirical, and clinical advances. Frontiers in Systems Neuroscience, 7(July), 31. doi:10.3389/fnsys.2013.00031

Rönnberg, J., Rudner, M., Lunner, T., \& Zekveld, A. A. (2010). When cognition kicks in: Working memory and speech understanding in noise. Noise and Health, A Bimonthly Interdisciplinary International Journal, 12(49). Retrieved from http://www.noiseandhealth.org/article.asp?issn=14631741; year=2010; volume=12;issue=49; spage=263; epage=269; aulast=R $\geqslant$ nnberg

Sadeghi, M. (2005). Usher syndrome. Prevalence and phenotype-genotype correlations. Gothenburg University: Department of Audiology.

Sadeghi, M., Cohn, E. S., Kelly, W. J., Kimberling, W. J., Tranebjoerg, L., \& Möller, C. (2004). Audiological findings in Usher syndrome types Ila and II (non-Ila). International Journal of Audiology, 43, 136-143. doi:10.1080/14992020400050019

Sadeghi, M., Kimberling, W., Tranebjœrg, L., \& Möller, C. (2004). The prevalence of Usher Syndrome in Sweden: a nationwide epidemiological and clinical survey. Audiological Medicine, 2(13), 220-228. doi:10.1080/16513860410003093

Santos, F. H., Bueno, O. F. a, \& Gathercole, S. E. (2006). Errors in nonword repetition: bridging short- and long-term memory. Brazilian Journal of Medical and Biological Research = Revista Brasileira de Pesquisas Médicas E Biológicas / Sociedade Brasileira de Biofísica ... [et Al.], 39(3), 371-85. doi:/S0100-879X2006000300008 
Saremi, A., \& Stenfelt, S. (2011). A physiological signal transmission model to be used for specific diagnosis of cochlear impairments. AIP Conference Proceedings, 1403, 369373. doi:10.1063/1.3658113

Schick, B., de Villiers, P., de Villiers, J., \& Hoffmeister, R. (2007). Language and theory of mind: a study of deaf children. Child Development, 78(2), 376-96. doi:10.1111/j.14678624.2007.01004.x

Schweitzer, C. (1997). Development of Digital Hearing Aids. Trends in Amplification, 2(2), 41-77. doi:10.1177/108471389700200202

Shafto, M. A, Burke, D. M., Stamatakis, E. A, Tam, P. P., \& Tyler, L. K. (2007). On the tip-ofthe-tongue: neural correlates of increased word-finding failures in normal aging. Journal of Cognitive Neuroscience, 19, 2060-2070. doi:10.1162/jocn.2007.91212

Sharma, A., Nash, A. A, \& Dorman, M. (2009). Cortical development, plasticity and reorganization in children with cochlear implants. Journal of Communication Disorders, 42(4), 272-9. doi:10.1016/j.jcomdis.2009.03.003

Shelton, J. T., Elliott, E. M., Hill, B. D., Calamia, M. R., \& Gouvier, W. D. (2009). A comparison of laboratory and clinical working memory tests and their prediction of fluid intelligence. Intelligence, 37(3), 283-293. doi:10.1016/j.intell.2008.11.005

Slade, L. (2005). How language does (and does not) relate to theory of mind: a longitudinal study of syntax, semantics, working memory and false belief, 117-141. doi:10.1348/026151004X21332

Spencer, L. J., \& Tomblin, J. B. (2009). Evaluating phonological processing skills in children with prelingual deafness who use cochlear implants. Journal of Deaf Studies and Deaf Education, 14(1), 1-21. doi:10.1093/deafed/enn013

Sundqvist, A., Lyxell, B., Jönsson, R., \& Heimann, M. (2014). Understanding minds: Early cochlear implantation and the development of theory of mind in children with profound hearing impairment. International Journal of Pediatric Otorhinolaryngology, 78, 538-544. doi:10.1016/j.ijporl.2013.12.039

Théoret, H., Merabet, L., \& Pascual-Leone, A. (2004). Behavioral and neuroplastic changes in the blind: Evidence for functionally relevant cross-modal interactions. Journal of Physiology Paris, 98(1-3 SPEC. ISS.), 221-233. doi:10.1016/j.jphysparis.2004.03.009

Thompson, G. B., Connelly, V., Fletcher-Flinn, C. M., \& Hodson, S. J. (2009). The nature of skilled adult reading varies with type of instruction in childhood. Memory \& Cognition, 37(2), 223-234. doi:10.3758/MC.37.2.223 
Torppa, M., Tolvanen, A., Poikkeus, A. M., Eklund, K., Lerkkanen, M. K., Leskinen, E., \& Lyytinen, H. (2007). Reading development subtypes and their early characteristics. Annals of Dyslexia, 57(1), 3-32. doi:10.1007/s11881-007-0003-0

Wahlqvist, M., Möller, C., Möller, K., \& Danermark, B. (2013). Physical and Psychological Health in Persons with Deafblindness That Is Due to Usher Syndrome Type II, Journal of Visual Impairment \& Blindness (May-June), 207-221.

Vallar, G., Di Betta, A. M., \& Silveri, M. C. (1997). The phonological short-term storerehearsal system: patterns of impairment and neural correlates. Neuropsychologia, 35(6), 795-812. Retrieved from http://www.ncbi.nlm.nih.gov/pubmed/9204486

Van Wijk, E., Pennings, R. J. E., te Brinke, H., Claassen, A., Yntema, H. G., Hoefsloot, L. H., ... Kremer, $\mathrm{H}$. (2004). Identification of 51 novel exons of the Usher syndrome type 2A (USH2A) gene that encode multiple conserved functional domains and that are mutated in patients with Usher syndrome type II. American Journal of Human Genetics, 74, 738-744. doi:10.1086/383096

Wass, M. (2009). Children with Cochlear Implants: Cognition and Reading Ability, (503). Linköping: Linköping University Press. Retrieved from http://www.divaportal.org/smash/record.jsf?pid=diva2:277216

Vecchi, T., Tinti, C., \& Cornoldi, C. (2004a). Spatial memory and integration processes in congenital blindness. NeuroReport, 15(18) 2787-2790. Retrieved from http://journals.Iww.com/neuroreport/Fulltext/2004/12220/Spatial_memory_and_inte gration_processes_in.20.aspx

Welcome, S. E., \& Joanisse, M. F. (2012). Individual differences in skilled adult readers reveal dissociable patterns of neural activity associated with component processes of reading. Brain and Language, 120(3), 360-371. doi:10.1016/j.bandl.2011.12.011

Wellman, H. M., Fang, F., \& Peterson, C. C. (2011). Sequential progressions in a theory-ofmind scale: longitudinal perspectives. Child Development, 82(3), 780-92.

doi:10.1111/j.1467- $\square 8624.2011 .01583 . x$

Verhoeven, L., \& Perfetti, C. A. (2011). Introduction to this Special Issue: Vocabulary Growth and Reading Skill. Scientific Studies of Reading, 15(791402039), 1-7.

doi:10.1080/10888438.2011.536124

White, S., Hill, E., Happé, F., \& Frith, U. (2009). Revisiting the strange stories: Revealing mentalizing impairments in autism. Child Development, 80(4), 1097-1117.

doi:10.1111/j.1467-8624.2009.01319.x 



\section{Papers}

The articles associated with this thesis have been removed for copyright reasons. For more details about these see:

http://urn.kb.se/resolve?urn=urn:nbn:se:liu:diva-120114 



\section{Studies from the Swedish Institute for Disability Research}

1. Varieties of reading disability

Stefan Gustafson

ISBN 91-7219-867-2, 2000

2. Cognitive functions in drivers with brain injury - anticipation and adaptation Anna Lundqvist

ISBN 91-7219-967-9, 2001

3. Cognitive deafness

Ulf Andersson

ISBN 91-7373-029-7, 2001

4. Att lära sig leva med förvärvad hörselnedsättning sett ur par-perspektiv

Carin Fredriksson

ISBN 91-7373-105-6, 2001

5. Signs, Symptoms, and Disability Related to the Musculo-Skeletal System Gunnar Lundberg

ISBN 91-7373-160-9, 2002

6. Participation - Ideology and Everyday Life

Anette Kjellberg

ISBN 91-7373-371-7, 2002

7. Föräldrar med funktionshinder - om barn, föräldraskap och familjeliv

Marie Gustavsson Holmström

ISBN 91-7203-500-5, 2002

8. Active wheelchair use in daily life

Kersti Samuelsson

ISBN 91-7373-196-X, 2002

9. Två kön eller inget alls. Politiska intentioner och vardagslivets realiteter i den arbetslivsinriktade rehabiliteringen

Marie Jansson

ISBN 91-7373-568-X, 2003 
10. Audiological and cognitive long-term sequelae from closed head injury Per-Olof Bergemalm

ISBN 91-7668-384-2, 2004

11. Att vara i särklass - om delaktighet och utanförskap i gymnasiesärskolan Martin Molin

ISBN 91-85295-46-9, 2004

12. Rättvis idrottsundervisning för elever med rörelsehinder - dilemma kring omfördelning och erkännande

Kajsa Jerlinder

Licentiate Degree, 2005

13. Hearing impairment and deafness. Genetic and environmental factors interactions - consequences. A clinical audiological approach

Per-Inge Carlsson

ISBN 91-7668-426-1, 2005

14. Hearing and cognition in speech comprehension. Methods and applications Mathias Hällgren

ISBN 91-85297-93-3, 2005

15. Living with deteriorating and hereditary disease: experiences over ten years of persons with muscular dystrophy and their next of kin

Katrin Boström

ISBN 91-7668-427-x, 2005

16. Disease and disability in early rheumatoid arthritis

Ingrid Thyberg

ISBN 91-85299-16-2, 2005

17. "Varför får jag icke följa med dit fram?" Medborgarskapet och den offentliga debatten om dövstumma och blinda 1860-1914

Staffan Bengtsson

ISBN 91-85457-06-X, 2005

18. Modalities of Mind. Modality-specific and nonmodality-specific aspects of working memory for sign and speech

Mary Rudner

ISBN 91-85457-10-8, 2005 
19. Facing the Illusion Piece by Piece. Face recognition for persons with learning disability

Henrik Danielsson

ISBN 91-85497-09-6, 2006

20. Vuxna med förvärvad traumatisk hjärnskada - omställningsprocesser och konsekvenser i vardagslivet. En studie av femton personers upplevelser och erfarenheter av att leva med förvärvad traumatisk hjärnskada

Thomas Strandberg

ISBN 91-7668-498-9, 2006

21. Nycklar till kommunikation. Kommunikation mellan vuxna personer med grav förvärvad hjärnskada och personernas närstående, anhöriga och personal

Pia Käcker

ISBN 978-91-85715-88-6, 2007

22. "Aspergern, det är jag". En intervjustudie om att leva med Asperger syndrom

Gunvor Larsson Abbad

ISBN 978-91-85831-43-2, 2007

23. Sounds of silence - Phonological awareness and written language in children with and without speech

Janna Ferreira

ISBN 978-91-85895-74-8, 2007

24. Postponed Plans: Prospective Memory and Intellectual Disability

Anna Levén

ISBN 978-91-85895-57-1, 2007

25. Consequences of brain tumours from the perspective of the patients and of their next of kin

Tanja Edvardsson

ISBN 978-91-7668-572-3, 2008

26. Impact on participation and service for persons with deafblindness

Kerstin Möller

ISBN 978-91-7668-595-2, 2008

27. Approaches to Audiological Rehabilitation with Hearing Aids: studies on prefitting strategies and assessment of outcomes

Marie Öberg

ISBN 978-91-7393-828-0, 2008 
28. Social Interaction and Participation in Activities of Everyday Life Among Persons with Schizophrenia

Maria Yilmaz

Licentiate Degree, 2009

29. Focus on Chronic Disease through Different Lenses of Expertise

Towards Implementation of Patient-Focused

Decision Support Preventing Disability:

The example of Early Rheumatoid Arthritis

Örjan Dahlström

ISBN 978-91-7393-613-2, 2009

30. Children with Cochlear Implants: Cognition and Reading Ability

Malin Wass

ISBN: 978-91-7393-487-9, 2009

31. Restricted participation:

Unaccompanied children in interpreter-mediated asylum hearings in Sweden

Olga Keselman

ISBN: 978-91-7393-499-2, 2009

32. Deaf people and labour market in Sweden.

Education - Employment - Economy

Emelie Rydberg

ISBN: 978-91-7668-725-3, 2010

33. Social rättvisa i inkluderande idrottsundervisning

för elever med rörelsehinder - en utopi?

Kajsa Jerlinder

ISBN: 978-91-7668-726-0, 2010

34. Erfarenheter av rehabiliteringsprocessen mot ett arbetsliv

- brukarens och de professionellas perspektiv

Helene Hillborg

ISBN: 978-91-7668-741-3, 2010

35. Knowing me, knowing you - Mentalization abilities of children who use augmentative and alternative communication

Annette Sundqvist

ISBN: 978-91-7393-316-2, 2010 
36. Lärare, socialsekreterare och barn som far illa - om sociala representationer och interprofessionell samverkan

Per Germundsson

ISBN: 978-91-7668-787-1, 2011

37. Fats in Mind

Effects of Omega-3 Fatty Acids on Cognition and Behaviour in Childhood

Ulrika Birberg Thornberg

ISBN: 978-91-7393-164-9, 2011

38. "Jobbet är kommunikation"

Om användning av arbetshjälpmedel för personer med hörselnedsättning

Sif Bjarnason

Licentiate Degree. ISBN: 978-91-7668-835-9, 2011

39. Applying the ICF-CY to identify everyday life situations of children and youth with disabilities

Margareta Adolfsson

ISBN: 978-91-628-8342-3, 2011

40. Tinnitus - an acceptance-based approach

Vendela Zetterqvist

ISBN: 978-91-7393-040-6, 2011

41. Applicability of the ICF-CY to describe functioning and environment of children with disabilities

Nina Klang

ISBN: 978-91-7668-864-9, 2012

42. Bringing more to participation

Participation in school activities of persons with Disability within the framework of the International Classification of Functioning, Disability and Health for Children and Youth (ICF-CY)

Gregor Maxwell

ISBN: 978-91-628-8484-0, 2012

43. From Eye to Us.

Prerequisites for and levels of participation in mainstream school of persons with Autism Spectrum Conditions

Marita Falkmer

ISBN: 978-91-637-2091-8, 2013 
44. Otosclerosis, clinical long-term perspectives

Ylva Dahlin-Redfors

ISBN 978-91-628-8617-2, 2013

45. Tinnitus in Context - A Contemporary Contextual Behavioral Approach Hugo Hesser

ISBN 978-91-7519-701-2, 2013

46. Hearing and middle ear status in children and young adults with cleft palate Traci Flynn

ISBN 978-91-628-8645-5, 2013

47. Utrymme för deltagande, beslutsprocesser i möten mellan patienter med ospecifika ländryggsbesvär och sjukgymnaster i primär vård

Iréne Josephson

ISBN 42-978-91-85835-41-6, 2013

48. "Man vill ju klara sig själv" Studievardagen för studenter med Asperger syndrom i högre studier

Ann Simmeborn Fleischer

ISBN 978-91-628-8681-3, 2013

49. Cognitive erosion and its implications in Alzheimer's disease

Selina Mårdh

ISBN 978-91-7519-621-1, 2013

50. Hörselscreening av en population med utvecklingsstörning

Utvärdering av psykoakustisk testmetod och av OAE-registrering som komplementär metod

Eva Andersson

Licentiate Degree. ISBN 978-91-7519-616-9, 2013

51. Skolformens komplexitet - elevers erfarenheter av skolvardag och tillhörighet i gymnasiesärskolan

Therése Mineur

ISBN 978-91-7668-951-6, 2013

52. Evaluating the process of change:

Studies on patient journey, hearing disability acceptance and stages-of-change

Vinaya Kumar Channapatna Manchaiah

ISBN 978-91-7519-534-6, 2013 
53. Cognition in hearing aid users: Memory for everyday speech

Hoi Ning (Elaine) $\mathrm{Ng}$

ISBN 978-91-7519-494-3, 2013

54. Representing sounds and spellings Phonological decline and compensatory working memory in acquired hearing impairment

Elisabet Classon

ISBN 978-91-7519-500-1, 2013

55. Assessment of participation in people with a mild intellectual disability

Patrik Arvidsson

ISBN 978-91-7668-974-5, 2013

56. Barnperspektiv i barnavårdsutredningar - med barns hälsa och barns

upplevelser i fokus

Elin Hultman

ISBN 978-91-7519-457-8, 2013

57. Internet Interventions for Hearing Loss

Examining rehabilitation Self-report measures and Internet use in hearing-aid users

Elisabet Sundewall Thorén

ISBN 978-91-7519-423-3, 2014

58. Exploring Cognitive Spare Capacity: Executive Processing of Degraded Speech Sushmit Mishra

ISBN 978-91-7519-386-1, 2014

59. Supported employment i en svensk kontext - förutsättningar när personer med funktionsnedsättning når, får och behåller ett arbete

Johanna Gustafsson

ISBN 978-91-7529-012-6, 2014

60. Effects of Specific Cochlear Pathologies on the Auditory Functions:

Modelling, Simulations and Clinical Implications

Amin Saremi

ISBN 978-91-7519-365-6, 2014 
61. Children with profound intellectual and multiple disabilities and their participation in family activities

Anna Karin Axelsson

ISBN 978-91-85835-48-5, 2014

62. Lexical and Semantic Development in Children With Cochlear Implants

Ulrika Löfkvist

ISBN 978-91-7549-546-0, 2014

63. Rethinking sound. Computer-assisted reading intervention with a phonics approach for deaf and hard of hearing children using cochlear implants or hearing aids

Cecilia Nakeva von Mentzer

ISBN 978-91-7519-270-3, 2014

64. Assessing cognitive spare capacity as a measure of listening effort using the Auditory Inference Span Test

Niklas Rönnberg

ISBN 978-91-7519-267-3, 2014

65. Employees with Aided Hearing Impairment: An Interdisciplinary Perspective Håkan Hua

ISBN 978-91-7519-240-6, 2014

66. Prosthetic and Orthotic Services in Developing Countries

Lina Magnusson

ISBN 978-91-85835-55-3, 2014

67. Dealing with digits - Arithmetic, memory and phonology in deaf signers Josefine Andin

ISBN: 978-91-7519-235-2, 2014

68. Time is of the essence in speech recognition: Get it fast or think about it Shahram Moradi

ISBN: 978-91-7519-188-1, 2014

69. Effects of hearing loss on traffic safety and mobility Aspekter på lärande vid dövblindhet

Birgitta Thorslund

ISBN: 978-91-7519-178-2, 2014 
70. Aspekter på lärande vid dövblindhet - möjligheter och begränsningar för personer med Alström syndrom

Berit Rönnåsen

Licentiate Degree. ISBN: 978-91-7529-068-3, 2015

71. Memory and communication in typically developing infants and children with Autism Spectrum Disorder: Bahavioral and electrophysiological indices

Emelie Nordqvist

ISBN: 978-91-7519-078-5, 2015 